\title{
Mechanomyogram and Electromyogram Responses of Upper Limb During Sustained Isometric Fatigue with Varying Shoulder and Elbow Postures
}

\author{
Nasser Koleini Mamaghani ${ }^{1)}$, Yoshihiro Shimomura ${ }^{2)}$, \\ Koichi Iwanaga ${ }^{1)}$ and Tetsuo Katsuura ${ }^{2)}$
}

1) Ergonomics Section, Graduate School of Science and Technology, Chiba University

2) Ergonomics Section, Department of Design and Architecture, Faculty of Engineering, Chiba University

\begin{abstract}
To investigate the behavior of mechanomyogram (MMG) and electromyogram (EMG) signals in the time and frequency domains during sustained isometric contraction, MMG and surface EMG were obtained simultaneously from four muscles: upper trapezius (TP), anterior deltoid (DL), biceps brachii (BB), and brachioradialis (BR) of 10 healthy male subjects. Experimental conditions consisted of 27 combinations of 9 postures [ 3 shoulder angles (SA): $0^{\circ}, 30^{\circ}, 60^{\circ}$ and 3 elbow angles (EA): $120^{\circ}, 90^{\circ}, 60^{\circ}$ ] and 3 contraction levels: $20 \%, 40 \%$, and $60 \%$ of maximum voluntary contraction (MVC). Subjective evaluations of fatigue were also assessed using the Borg scale at intervals of 60 , 30 , and $10 \mathrm{sec}$ at $20 \%, 40 \%$, and $60 \%$ MVC tests, respectively. The mean power frequency (MPF) and root mean square (RMS) of both signals were calculated. The current study found clear and significant relationships among physiological and psychological parameters on the one hand and SA and EA on the other. EA's effect on MVC was found to be significant. SA had a highly significant effect on both endurance time and Borg scale. In all experimental conditions, significant correlations were found between the changes in MPF and RMS of EMG in BB with SA and EA (or muscle length). In all four muscles, MMG frequency content was two or three times lower than EMG frequency content. During sustained isometric contraction, the EMG signal showed the wellknown shift to lower frequencies (a continuous decrease from onset to completion of the contraction). In contrast, the MMG spectra did not show any shift, although its form changed (generally remaining about constant). Throughout the contraction, increased RMS of EMG was found for all tests, whereas in the MMG signal, a significant progressive increase in RMS was observed only at $20 \% \mathrm{MVC}$ in all four muscles. This supports the
\end{abstract}

hypothesis that the RMS amplitude of the MMG signal produced during contraction is highly correlated with force production. Possible explanations for this behavioral difference between the MMG and EMG signals are discussed. J Physiol Anthropol 21 (1): 29-43, 2002 http://www.jstage.jst.go.jp/en/

Keywords: mechanomyogram, EMG, muscle fatigue, Borg scale, shoulder and elbow flexion

\section{Introduction}

Several investigations have shown that the voluntary contraction of muscles is accompanied by vibratory signals that can be detected at the muscle surface by a variety of transducers. The vibratory signal is considered to be associated with the mechanical activities of a number of muscle fibers and to reflect the motor unit (MU) activation strategy relating to force generation (Barry et al., 1985; Gordon and Holbourn, 1948; Orizio, 1993). The detection and measurement of this signal has been referred to variously as accelerometermyogram (Lammert et al., 1976), muscle sound (Oster and Jaffe, 1980), acoustic myogram (Barry et al., 1985), soundmyogram (Orizio et al., 1989b), vibromyogram (Keidel and Keidel, 1989) or phonomyogram (Maton et al., 1990). More recently, in order to indicate clearly the nature of the signal, the term surface mechanomyogram (MMG) has been suggested (Orizio, 1993). This is a more accurate and global term than the others, because it emphasizes the mechanical nature of the phenomenon independently of the transducer used to detect it. Accordingly, we adopted this term in our study. Piezoelectric contact sensors (Barry, 1991; Bolton et al., 
1989; Orizio et al., 1994), condenser microphones (Bolton et al., 1989; Maton et al., 1990; Stokes and Dalton, 1991b) and accelerometers (Barry, 1992; Lammert et al., 1976; Orizio et al., 1996) have been widely used to detect MMG. The MMG waveform recorded by a piezoelectric contact sensor was similar to that recorded by a condenser microphone (Bolton et al., 1989), but it was markedly different from the signal recorded by an accelerometer (Barry, 1992).

In contrast to electromyographic (EMG) signals, the MMG appears to more directly reflect contractile properties of muscles, so it may also aid in examining various aspects of muscle function including muscle fatigue (Herzog et al., 1994; Koleini et al., 2000; Orizio et al., 1989a), muscle fiber type pattern (Mealing et al., 1996), age-related changes in muscular performance (Esposito et al., 1996), muscle atrophy (Marchetti et al., 1974), and neuromuscular disorders (Akataki et al., 1996). Several studies have examined muscle fatigue responses in MMG signals and fatigue-related changes in MU recruitment and firing rates (Goldenberg et al., 1991). It has been reported that the MMG frequency components reflect active MU firing rates, and that the MMG amplitude represents mainly the mechanical properties of contraction, muscle fiber composition, and firing rate during voluntary contraction (Yoshitake and Moritani, 1999). Moreover, the changes in the activation of MU due to fatigue strongly influence the MMG amplitude (Barry et al., 1985; Orizio et al., 1989a; Zwarts and Keidel, 1991).

A factor of subjective fatigue could also be added to the concept of fatigue (Simonson and Weiser, 1976). As a subjective assessment of fatigue, the Borg category ratio 10 (CR-10) scale (Borg, 1990) has become an accepted way to measure subjective estimates of fatigue in a range of exertion studies. This scale's mathematical properties permit statistical calculations. Few studies have dealt with subjective assessment correlated with objective findings (Kankaanpaa et al., 1997). Thus, in this study Borg's category ratio scale (Borg, 1982) was also used to subjectively evaluate muscle fatigue.

Muscle fatigue related to changes in EMG parameters occurs during sustained contractions, as various studies have noted. On the other hand, the study of MMG signals has been renewed in recent years with advances in sensing devices and computers (i.e., the possibility of applying signal processing techniques to a large number of signal samples), but characterization and interpretation of the signals still need further attention. Since both the MMG (Barry, 1987; Mealing et al., 1990; Orizio et al., 1990; Oster and Jaffe, 1980; Zhang et al., 1990) and EMG (De Luca, 1979; Nagata et al., 1990) picked up over the surface of active skeletal muscle would be expected to measure the state of muscle activation, we searched the literature for studies of MMG with EMG simultaneously recorded on the same muscles to determine their relative properties with levels of contraction, but we found few articles.

The main purposes of the study reported here were to examine changes in the frequency and amplitude characteristics of the MMG signal with its EMG signal as objective measures of muscle fatigue, and to apply Borg scale as a subjective estimate of fatigue at different levels of voluntary contraction at different joint angles. Thus our experiments were designed 1) to describe the changes in both signal parameters during sustained isometric contraction at constant force until exhaustion, 2) to study the relationship between MMG and EMG signal parameters with force, and 3) to study the similarities and differences between MMG and EMG characteristics under the same muscle activation state. An additional aim of the current study was to assess whether the changes in characteristics of the MMG and EMG signals depended on joint angle or muscle length.

\section{Methods}

\section{Subjects and experimental procedures}

Ten young healthy male subjects participated in this study. Their mean (SD) age, height, and body mass were 24 (1.2) years, $171(5) \mathrm{cm}$, and $61.3(5.8) \mathrm{kg}$, respectively. All of the subjects were right-handed. Experimental conditions consisted of 27 combinations of 9 postures [ 3 shoulder angles $\left(0^{\circ}, 30^{\circ}, 60^{\circ}\right)$ and 3 elbow angles $\left(120^{\circ}\right.$, $90^{\circ}, 60^{\circ}$ )] and 3 contraction levels, namely $20 \%, 40 \%$, and $60 \%$ of maximum voluntary contraction (MVC).

The experimental device was similar to that used and illustrated in our previous study (Koleini et al., 2001) and is only briefly described here. Each subject was seated in a straight-backed chair with both the knees and hips flexed at $90^{\circ}$. In the sagittal plane, shoulder angle (SA) was defined as the angle between the midline of the upper arm and the line joining the shoulder and hip joints. Elbow angle (EA) was defined as the angle between the midlines of the upper arm and lower arm. An electrogoniometer (Penny \& Giles Co.) was attached to the lateral side of the shoulder, and another was attached to the elbow. The experiment began with the determination of the individual MVC according to the Caldwell protocol (Caldwell et al., 1974) at designated postures using a strain gauge dynamometer with a load cell (Model 1269, Takei Kiki Kogyo Co.). The highest of three MVC measurements was considered the MVC. This procedure was repeated during each experiment. Each subject was instructed to hold a weight (equal to the designated \%MVC) suspended by a strap from the weight handle, and was asked to maintain this position for as long as possible until exhaustion. The electrogoniometer signal output was displayed on a computer screen positioned directly in front of the subject. Two horizontal lines, indicating the required angle, were superimposed 
on the screen to provide feedback to the subject. The degree of subjective feeling of fatigue was also assessed using the Borg scale every 60,30 , and 10 sec during the $20 \%, 40 \%$, and $60 \%$ MVC tests, respectively, with the scale ranging from 0 to 100 (Borg, 1982).

\section{Signal acquisition and processing}

MMG and EMG signals were recorded from four muscles: 1) the upper trapezius (TP) as an important stabilizer of the shoulder joint, 2) the anterior deltoid (DL) as the prime mover of forward flexion of the arm, 3) biceps brachii (BB) as a primary muscle at elbow flexion, and 4) brachioradialis (BR) as a particular or controversial participation muscle at elbow flexion. EMG was recorded using disposable surface electrodes (Vitrode Y, Nihon Kohden), and the MMG was recorded by an accelerometer (Model MT-3T, diameter: $23 \mathrm{~mm}$, thickness: $6.5 \mathrm{~mm}$, weight: $3 \mathrm{~g}$, Nihon Kohden), which was secured between EMG electrodes. The EMG and MMG signals were amplified by AC bio-amplifiers (Model AB-621G, Nihon Kohden). The signals were also low-pass filtered with a cutoff frequency of $300 \mathrm{~Hz}$ (time constant of $0.03 \mathrm{sec}$ ) and $100 \mathrm{~Hz}$ (time constant of $0.1 \mathrm{sec}$ ) for EMG and MMG, respectively. The raw EMG and MMG signals were simultaneously and continuously stored on a personal computer after analog-to-digital (A/D) conversion at a sampling rate of $1000 \mathrm{~Hz}$.

\section{Data analysis}

In this study, endurance time was defined as the duration in which the subject maintained the target angle without deviation of more than $\pm 10^{\circ}$. Because the endurance time varied between subjects, we normalized the time in the contraction by setting the endurance time as $100 \%$. The endurance time of each subject was divided into 10 equal segments. At the first second of each 10th percentile of endurance time (as a sample of recorded data) as well as at the last second of contraction, the frequency spectrum and mean power frequency (MPF) of each of the EMG $\left(\mathrm{MPF}_{\mathrm{EMG}}\right)$ and $\mathrm{MMG}\left(\mathrm{MPF}_{\mathrm{MMG}}\right)$ signals were calculated using a Fast Fourier Transform (FFT) with a Hanning window of 1024 points. To represent the amplitude changes, the root mean squared (RMS) values of the EMG $\left(\mathrm{RMS}_{\mathrm{EMG}}\right)$ and MMG $\left(\mathrm{RMS}_{\mathrm{MMG}}\right)$ signals were computed from the digitized data in each sample in the time domain. To enable data to be compared between subjective evaluation (Borg scale) and objective assessment (EMG and MMG signals) of fatiguing contractions, the Borg scale data were normalized by the following method. A Lagrange polynomial function was used to interpolate data. The corresponding point of endurance time at this interpolation curve was considered as the maximum on the Borg scale (100\%). Normalized Borg scale data were calculated at every 10th percentile of endurance time, so that a sample of 11 points (from 0 to 100\%) was obtained. Best fitting curve was obtained using the nonlinear power function regression. Then, the time constant of each regression curve was computed for use in the analysis of Borg scale data. This method was repeated for each subject, in all experimental conditions.

Repeated measures analysis of variance (ANOVA) was used for statistical analysis. This analysis was performed using StatView 5.0. Four-way repeated measures ANOVAs (SA $\times \mathrm{EA} \times \% \mathrm{MVC} \times$ time) were used to analyze the EMG and MMG frequency (MPF) and amplitude (RMS) data. Follow-up for the endurance time and Borg scale data three-way $(\mathrm{SA} \times \mathrm{EA} \times \% \mathrm{MVC})$ ANOVAs were used, and for MVC data two-way $(\mathrm{SA} \times \mathrm{EA}$ ) repeated measures ANOVA were used. The Pearson correlation coefficient was used to correlate parametric data. A probability level of $\mathrm{P}<0.05$ was considered statistically significant for all comparisons.

\section{Results}

\section{$M V C$ and endurance time}

The MVC and endurance time results are reported in Table 1 . The mean values of MVC increased with increased SA or with decreased EA. The greatest MVC occurred at $\mathrm{SA} 60^{\circ}-\mathrm{EA} 60^{\circ}$. The ANOVA results showed a significant main effect of EA on MVC, whereas SA was not significant. However, a significant interaction was observed between the SA and EA on MVC. Table 1 shows that endurance time clearly declined with increased SA and \%MVC. As expected, the effect of \%MVC on endurance time was significant. In regard to the effect of joint angle on endurance time, there was no significant effect of EA, but the effect of SA was highly significant $(p<0.0001)$. A significant interaction was observed between the SA and \%MVC on endurance time.

\section{Borg scale}

Figure 1 shows the average values of Borg scale rating as a function of time (normalized to endurance time) throughout sustained isometric contraction in the 27 experimental conditions. In these conditions, the Borg curves clearly differed from the beginning to the end of the test. The difference was particularly obvious between the low and high levels of contraction and between different SA, while no difference was observed for EA except for the conditions of $\mathrm{SA} 0^{\circ}-60 \% \mathrm{MVC}$. The results of Borg rating values indicate that the time constant of curves declined with increased \%MVC; in contrast, it increased with increased SA. The smallest and the biggest means (SD) of time constant values were 14.1 (11.1) sec and 40.1 (12.0) sec at the condition of SA0 ${ }^{\circ}$ $60 \% \mathrm{MVC}$ and SA $60^{\circ}-20 \% \mathrm{MVC}$, respectively. Moreover, the three-way ANOVA revealed a significant main effect of $\mathrm{SA}$ and \% $\mathrm{MVC}$ on the time constant of Borg rating 
Table 1 Mean \pm SD values of maximum voluntary contraction (MVC) at 9 different postures ( 3 shoulder angles $\times 3$ elbow angles) and endurance times of sustained isometric contraction under 27 experimental conditions $(n=10)$

\begin{tabular}{|c|c|c|c|c|c|c|c|c|c|c|}
\hline \multirow{2}{*}{\multicolumn{2}{|c|}{$\begin{array}{l}\text { Shoulder angle (SA) } \\
\text { Elbow angle (EA) }\end{array}$}} & \multicolumn{3}{|c|}{$0^{\circ}$} & \multicolumn{3}{|c|}{$30^{\circ}$} & \multicolumn{3}{|c|}{$60^{\circ}$} \\
\hline & & $120^{\circ}$ & $90^{\circ}$ & $60^{\circ}$ & $120^{\circ}$ & $90^{\circ}$ & $60^{\circ}$ & $120^{\circ}$ & $90^{\circ}$ & $60^{\circ}$ \\
\hline $\operatorname{MVC}(\mathrm{N})$ & $\% \mathrm{MVC}$ & $162 \pm 26$ & $168 \pm 24$ & $170 \pm 23$ & $130 \pm 28$ & $155 \pm 21$ & $197 \pm 42$ & $123 \pm 25$ & $155 \pm 36$ & $218 \pm 39$ \\
\hline \multirow[t]{3}{*}{ Endurance time (S) } & 20 & $562 \pm 187$ & $631 \pm 290$ & $600 \pm 283$ & $371 \pm 101$ & $389 \pm 174$ & $524 \pm 301$ & $290 \pm 130$ & $345 \pm 268$ & $346 \pm 187$ \\
\hline & 40 & $138 \pm 37$ & $115 \pm 28$ & $117 \pm 40$ & $81 \pm 26$ & $82 \pm 34$ & $88 \pm 22$ & $69 \pm 25$ & $81 \pm 27$ & $91 \pm 20$ \\
\hline & 60 & $61 \pm 28$ & $49 \pm 18$ & $48 \pm 20$ & $40 \pm 23$ & $37 \pm 12$ & $42 \pm 16$ & $37 \pm 16$ & $35 \pm 9$ & $46 \pm 19$ \\
\hline
\end{tabular}

$20 \%$ MVC
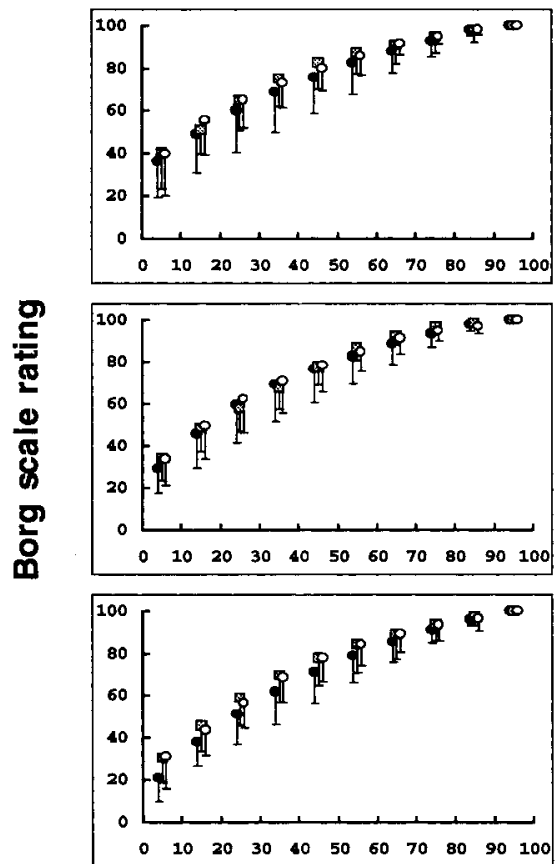

EA:

- $120^{\circ}$
$40 \%$ MVC
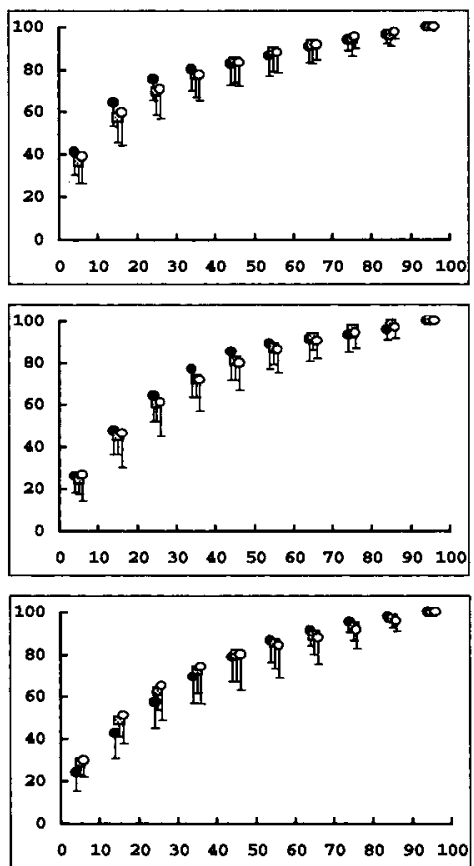

Time (\% endurance time)
$60 \%$ MVC
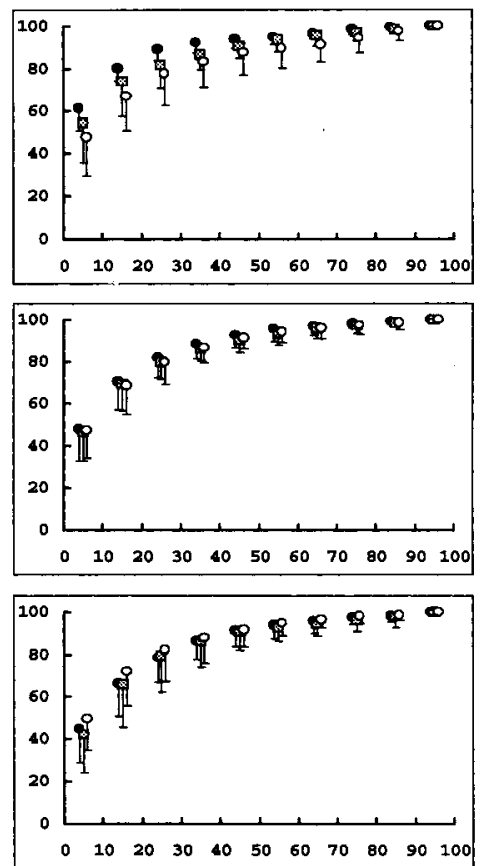

SA

$0^{\circ}$

$30^{\circ}$

$60^{\circ}$

Fig. 1 Changes in Borg scale rating as a function of time (expressed as a percentage of the endurance time) during sustained isometric contraction under 27 experimental conditions, provided by a combination of 3 shoulder angles (SA): $0^{\circ}, 30^{\circ}$, and $60^{\circ}, 3$ elbow angles (EA): $120^{\circ}(\mathbf{O}), 90^{\circ}$ ), and $60^{\circ}(\mathbf{O})$, and 3 levels of maximum voluntary contraction (MVC): 20\%, 40\%, and 60\% MVC. Each point is the average value (mean and $\mathrm{SD}, \mathrm{n}=10$ ) at every $10 \%$ endurance time.

curves, but the effect of EA was not significant.

\section{Mean power frequency (MPF)}

Table 2 shows the mean $\pm \mathrm{SD}$ of $\mathrm{MPF}_{\mathrm{EMG}}$ and $\mathrm{MPF}_{\mathrm{MMG}}$ values at the onset of contractions and the point when each of the four muscles became exhausted. It is seen that the MMG signal is two or three times lower than the EMG signal. The EMG signal decreased by more than 20 $\mathrm{Hz}$ between onset and exhaustion, but no such decrease was found for the MMG signal.

\section{MPF throughout sustained contraction}

The $\mathrm{MPF}_{\mathrm{EMG}}$ tended to decrease continuously throughout the sustained isometric contraction, whereas the corresponding $\mathrm{MPF}_{\mathrm{MMG}}$ typically remained almost constant from the onset to the end of contractions. Pearson correlation coefficients between changes in MPF and the corresponding time are reported in Table 3.

In all four muscles, $\mathrm{MPF}_{\mathrm{EMG}}$ of the power spectrum shifted toward lower frequencies in almost all experimental conditions. The ANOVA results showed a significant main effect of time (in all four muscles) on $\mathrm{MPF}_{\mathrm{EMG}}$. Neither the SA nor the EA factor was causally significant as an effect on $\mathrm{MPF}_{\mathrm{EMG}}$ in $\mathrm{TP}, \mathrm{DL}$, or BR, while in BB the effect of SA and that of EA (as well as \%MVC) were both highly significant $(p<0.0001)$. Figure 2 shows 
Table 2 Electromyogram (EMG) and mechanomyogram (MMG) mean power frequency (MPF, Hz) values (mean \pm SD) of four muscles at onset and exhaustion of sustained isometric contractions (averaged from each of 9 postures, $n=10$ )

\begin{tabular}{|c|c|c|c|c|c|c|c|}
\hline \multirow[b]{2}{*}{ MPF } & \multirow[b]{2}{*}{ Muscle } & \multicolumn{2}{|c|}{$20 \% \mathrm{MVC}$} & \multicolumn{2}{|c|}{$40 \% \mathrm{MVC}$} & \multicolumn{2}{|c|}{$60 \% \mathrm{MVC}$} \\
\hline & & Onset & Exhaustion & Onset & Exhaustion & Onset & Exhaustion \\
\hline \multirow[t]{4}{*}{ EMG } & $\mathrm{TP}$ & $107.9 \pm 3.5$ & $87.7 \pm 2.8$ & $105.4 \pm 2.6$ & $83.3 \pm 2.8$ & $104.5 \pm 2.9$ & $81.4 \pm 2.7$ \\
\hline & DL & $104.0 \pm 2.9$ & $80.8 \pm 3.8$ & $102.3 \pm 3.5$ & $74.7 \pm 4.8$ & $103.2 \pm 5.1$ & $74.5 \pm 5.0$ \\
\hline & $\mathrm{BB}$ & $107.3 \pm 8.8$ & $89.8 \pm 9.6$ & $106.1 \pm 6.6$ & $80.7 \pm 9.4$ & $105.1 \pm 7.0$ & $78.2 \pm 8.8$ \\
\hline & $\mathrm{BR}$ & $116.4 \pm 15.6$ & $103.4 \pm 15.5$ & $108.8 \pm 11.8$ & $97.9 \pm 12.7$ & $110.1 \pm 11.4$ & $95.8 \pm 10.8$ \\
\hline \multirow[t]{4}{*}{ MMG } & $\mathrm{TP}$ & $55.2 \pm 6.5$ & $61.0 \pm 9.0$ & $55.7 \pm 6.6$ & $63.7 \pm 8.5$ & $65.2 \pm 8.9$ & $70.9 \pm 9.0$ \\
\hline & DL & $44.7 \pm 5.1$ & $38.6 \pm 3.4$ & $42.7 \pm 3.4$ & $39.8 \pm 2.5$ & $42.8 \pm 4.5$ & $40.8 \pm 4.3$ \\
\hline & $\mathrm{BB}$ & $32.3 \pm 2.6$ & $33.3 \pm 4.7$ & $35.1 \pm 3.6$ & $35.9 \pm 3.4$ & $36.3 \pm 3.7$ & $37.4 \pm 4.2$ \\
\hline & $\mathrm{BR}$ & $32.4 \pm 4.9$ & $31.5 \pm 5.4$ & $35.2 \pm 6.4$ & $33.7 \pm 4.8$ & $35.8 \pm 5.9$ & $37.5 \pm 5.7$ \\
\hline
\end{tabular}

The muscles, TP: upper trapezius, DL: anterior deltoid, BB: biceps brachii, BR: brachioradialis.

the changes in $\mathrm{MPF}_{\mathrm{EMG}}$ in $\mathrm{BB}$ during sustained contraction at 27 different conditions. A significant effect of EA on $\mathrm{MPF}_{\mathrm{EMG}}$ value is clearly seen in this figure. In $\mathrm{BB}$, throughout the experiments, $\mathrm{MPF}_{\mathrm{EMG}}$ values of test contraction at $\mathrm{EA} 120^{\circ}$ were smaller than those at the other EA, and values of test contraction at EA90 ${ }^{\circ}$ were smaller than those at EA60 $0^{\circ}$.

In contrast to the EMG signal, $\mathrm{MPF}_{\mathrm{MMG}}$ did not shift toward lower frequency. Changes in the $\mathrm{MPF}_{\mathrm{MmG}}$ of $\mathrm{TP}$ (as a typical muscle among the four) were selected to show the behavior of MMG signal frequency during sustained contraction (Fig. 3). There were significant main effects of SA $(p<0.01$ to $p<0.0001)$, EA $(p<0.01$, except in the TP and the BB), \%MVC ( $<<0.05$ to $p<0.001)$, and time $(p<0.0001$, except in $\mathrm{BB})$ on $\mathrm{MPF}_{\mathrm{MMG}}$ for all four muscles.

\section{MPF as a function of force}

Figure 4 a shows the relationship between the level of contraction and $\mathrm{MPF}_{\mathrm{EMG}}$ and $\mathrm{MPF}_{\mathrm{MMG}}$. In this figure, the average MPF of both signals of a typical muscle (BB) are represented as a function of \%MVC. Consistent with previous findings, $\mathrm{MPF}_{\mathrm{EMG}}$ decreased, at both the onset and the end of contraction, almost linearly with increased contraction levels. In addition, the difference between the onset and exhaustion values of each contraction level increased as the force level increased. In contrast to the findings with EMG signal, it is clear from Fig. 4a that the MMG displayed entirely different behavior (except for the $\mathrm{DL})$. At the onset of contraction in $\mathrm{DL}, \mathrm{MPF}_{\mathrm{MMG}}$ decreased (as it did with EMG), but the relationship was the inverse of that with EMG: at exhaustion, $\mathrm{MPF}_{\mathrm{MMG}}$ increased with increased contraction level.

\section{Root mean square (RMS)}

Table 4 presents the mean $\pm \mathrm{SD}$ of $\mathrm{RMS}_{\mathrm{EMG}}$ and $\mathrm{RMS}_{\mathrm{MMG}}$ values at the onset of contraction and at exhaustion of each of the four muscles. It should be noted that $\mathrm{RMS}_{\mathrm{MMG}}$ values magnified 200 times their original output voltage of accelerometer. However, these values essentially indicate the same meaning of arbitrary units. As shown in Table 4, the smallest and the largest values of RMS for EMG were found for TP at 20\% MVC (onset: 0.03 $\mathrm{mV}$, exhaustion: $0.07 \mathrm{mV}$ ) and $\mathrm{DL}$ at $60 \% \mathrm{MVC}$ (onset: $0.63 \mathrm{mV}$, exhaustion: $1.32 \mathrm{mV}$ ), whereas for MMG it was found for TP at 20\% MVC (onset: $0.10 \mathrm{~V}$, exhaustion: 0.55 $\mathrm{V}$ ) and BB at 60\% MVC (onset: $4.84 \mathrm{~V}$, exhaustion: $6.82 \mathrm{~V}$ ), respectively.

\section{RMS throughout sustained contraction}

The correlation coefficients found in this study between the duration of contraction and the $\mathrm{RMS}_{\mathrm{EMG}}$ and $\mathrm{RMS}_{\mathrm{MMG}}$ values are reported in Table 5. A significant increase of $\mathrm{RMS}_{\mathrm{EMG}}$ throughout sustained isometric contraction was found for each of the four muscles under almost all experimental conditions. The correlation coefficients between $\mathrm{RMS}_{\mathrm{MMG}}$ and time showed a highly significant increase only in the $20 \%$ MVC experiments.

Changes in $\mathrm{RMS}_{\mathrm{EMG}}$ of $\mathrm{BB}$ during the test contraction are shown in Fig. 5. The results of repeated measures ANOVA revealed that \% MVC and time (except for BR) each had a causally significant effect on $\mathrm{RMS}_{\mathrm{EMG}}$. There was a significant main effect of $\mathrm{SA}$ on $\mathrm{RMS}_{\mathrm{EMG}}$ for all four muscles, while EA was highly significant for BB only. During the test contraction in $\mathrm{BB}$, the RMS value at $\mathrm{EA} 120^{\circ}$ was bigger than that at $\mathrm{EA} 90^{\circ}$ or $\mathrm{EA} 60^{\circ}$; also, the value at $\mathrm{EA} 90^{\circ}$ was bigger than at EA60 ${ }^{\circ}$. Only one muscle, BB, showed this kind of effect under all experimental conditions.

Figure 6 represents the changes in $\mathrm{RMS}_{\mathrm{MMG}}$ of $\mathrm{BR}$ under 27 experimental conditions throughout sustained isometric contraction. This figure shows clearly that $\mathrm{RMS}_{\mathrm{MMG}}$ behaves differently at a low level of contraction (20\% MVC) than at the other contraction levels (40\% and $60 \% \mathrm{MVC}$ ). At $20 \% \mathrm{MVC} \mathrm{RMS}_{\mathrm{MMG}}$ increased progressively from the beginning to the end of the test in all four muscles. At this $20 \%$ contraction, the $\mathrm{RMS}_{\mathrm{MMG}}$ values significantly increased with increased EA. The ANOVA 
Table 3 Pearson correlation coefficient between time of contraction and mean power frequency (MPF) values of electromyogram (EMG) and mechanomyogram (MMG) signals of four muscles during sustained isometric contractions under 27 experimental conditions $(n=10)$

\begin{tabular}{|c|c|c|c|c|c|c|c|}
\hline \multirow[b]{2}{*}{ SA } & \multirow[b]{2}{*}{ Muscle } & \multicolumn{2}{|c|}{$20 \% \mathrm{MVC}$} & \multicolumn{2}{|c|}{$40 \% \mathrm{MVC}$} & \multicolumn{2}{|c|}{$60 \% \mathrm{MVC}$} \\
\hline & & EMG & MMG & EMG & MMG & EMG & MMG \\
\hline \multirow[t]{12}{*}{$0^{\circ}$} & $\mathrm{TP}$ & $-0.26^{\star \star \star}$ & $0.20^{* *}$ & $-0.50^{* * *}$ & $0.26^{* * *}$ & $-0.46^{\star * *}$ & $0.10 \mathrm{~ns}$ \\
\hline & & $-0.32^{\star * *}$ & $0.03 \mathrm{~ns}$ & $-0.50^{* * *}$ & $0.08 \mathrm{~ns}$ & $-0.44^{\star * *}$ & $0.02 \mathrm{~ns}$ \\
\hline & & $-0.16 \mathrm{~ns}$ & $0.18^{*}$ & $-0.28^{\star \star \star}$ & $0.14 \mathrm{~ns}$ & $-0.39^{* \star *}$ & $-0.04 \mathrm{~ns}$ \\
\hline & $\overline{\mathrm{DL}}$ & $-0.38^{* * *}$ & $-0.21^{* *}$ & $-0.44^{* * *}$ & $0.14 \mathrm{~ns}$ & $-0.42^{\star * *}$ & $0.26^{\text {*** }}$ \\
\hline & & $-0.50^{* * *}$ & $-0.19^{*}$ & $-0.54^{\star * *}$ & $0.07 \mathrm{~ns}$ & $-0.47^{\star \star *}$ & $0.26^{\star \star \star *}$ \\
\hline & & $-0.60^{\star * *}$ & $-0.04 \mathrm{~ns}$ & $-0.58^{\star \star \star}$ & $0.10 \mathrm{~ns}$ & $-0.40^{\star \star \star}$ & $0.15 \mathrm{~ns}$ \\
\hline & $\mathrm{BB}$ & $-0.48^{\star * \star}$ & $-0.07 \mathrm{~ns}$ & $-0.64^{\star * *}$ & $0.11 \mathrm{~ns}$ & $-0.66^{\star \star \star}$ & $0.05 \mathrm{~ns}$ \\
\hline & & $-0.42^{\star * *}$ & $0.00 \mathrm{~ns}$ & $-0.72^{\star \star *}$ & $0.11 \mathrm{~ns}$ & $-0.76^{\star \star *}$ & $0.07 \mathrm{~ns}$ \\
\hline & & $-0.36^{\star * *}$ & $0.15 \mathrm{~ns}$ & $-0.57^{* * *}$ & $-0.03 \mathrm{~ns}$ & $-0.62^{* * *}$ & $-0.16^{*}$ \\
\hline & $\mathrm{BR}$ & $-0.27^{\star \star *}$ & $-0.09 \mathrm{~ns}$ & $-0.57^{\star \star \star}$ & $0.18^{*}$ & $-0.48^{* \star *}$ & $0.18^{*}$ \\
\hline & & $-0.22^{\star *}$ & $-0.13 \mathrm{~ns}$ & $-0.52^{* * *}$ & $0.06 \mathrm{~ns}$ & $-0.51^{\star * *}$ & $0.04 \mathrm{~ns}$ \\
\hline & & $-0.25^{\star \star}$ & $0.01 \mathrm{~ns}$ & $-0.50^{\star \star *}$ & $-0.26^{\star *}$ & $-0.49^{\star \star \star}$ & $-0.13 \mathrm{~ns}$ \\
\hline \multirow[t]{12}{*}{$30^{\circ}$} & $\mathrm{TP}$ & $-0.54^{\star * *}$ & $0.10 \mathrm{~ns}$ & $-0.62^{* * *}$ & $0.14 \mathrm{~ns}$ & $-0.55^{* * *}$ & $0.20^{* *}$ \\
\hline & & $-0.60^{* \star *}$ & $0.16 \mathrm{~ns}$ & $-0.56^{\star \star *}$ & $0.19^{* *}$ & $-0.61^{\star * *}$ & $0.10 \mathrm{~ns}$ \\
\hline & & $-0.46^{\star \star *}$ & $-0.02 \mathrm{~ns}$ & $-0.65^{\star * *}$ & $0.11 \mathrm{~ns}$ & $-0.59^{* * *}$ & $0.15 \mathrm{~ns}$ \\
\hline & $\mathrm{DL}$ & $-0.54^{\star \star \star}$ & $-0.17^{\star}$ & $-0.66^{\star \star \star *}$ & $-0.13 \mathrm{~ns}$ & $-0.61^{\star \star \star}$ & $-0.22^{\star \star}$ \\
\hline & & $-0.70^{\star \star \star}$ & $-0.22^{* *}$ & $-0.76^{\star * *}$ & $-0.25^{\star *}$ & $-0.62^{* * *}$ & $-0.28^{* * *}$ \\
\hline & & $-0.57^{\text {***}}$ & $-0.04 \mathrm{~ns}$ & $-0.79^{* * *}$ & $0.01 \mathrm{~ns}$ & $-0.72^{\star * *}$ & $-0.39^{\star * \star}$ \\
\hline & $\mathrm{BB}$ & $-0.35^{* * *}$ & $-0.08 \mathrm{~ns}$ & $-0.45^{* * *}$ & $0.15 \mathrm{~ns}$ & $-0.47^{\star \star *}$ & $-0.01 \mathrm{~ns}$ \\
\hline & & $-0.13 \mathrm{~ns}$ & $-0.15 \mathrm{~ns}$ & $-0.60^{\star \star *}$ & $-0.01 \mathrm{~ns}$ & $-0.53^{\star \star *}$ & $-0.07 \mathrm{~ns}$ \\
\hline & & $-0.19^{\star *}$ & $0.04 \mathrm{~ns}$ & $-0.48^{* * *}$ & $0.20^{* *}$ & $-0.63^{\star * *}$ & $-0.10 \mathrm{~ns}$ \\
\hline & $\mathrm{BR}$ & $-0.05 \mathrm{~ns}$ & $-0.03 \mathrm{~ns}$ & $-0.19^{* *}$ & $-0.08 \mathrm{~ns}$ & $-0.13 \mathrm{~ns}$ & $-0.05 \mathrm{~ns}$ \\
\hline & & $-0.25^{\star \star}$ & $-0.19^{\star}$ & $-0.23^{\star \star}$ & $0.04 \mathrm{~ns}$ & $-0.21^{\star \star}$ & $0.09 \mathrm{~ns}$ \\
\hline & & $-0.22^{\star}$ & $-0.11 \mathrm{~ns}$ & $0.03 \mathrm{~ns}$ & $-0.06 \mathrm{~ns}$ & $-0.34^{\star * *}$ & $0.15 \mathrm{~ns}$ \\
\hline \multirow[t]{12}{*}{$60^{\circ}$} & $\mathrm{TP}$ & $-0.53^{* * *}$ & $0.00 \mathrm{~ns}$ & $-0.52^{* * *}$ & $0.19^{* *}$ & $-0.66^{* * *}$ & $-0.07 \mathrm{~ns}$ \\
\hline & & $-0.70^{\star * *}$ & $0.07 \mathrm{~ns}$ & $-0.60^{\text {*** }}$ & $0.18^{*}$ & $-0.61^{* * *}$ & $0.09 \mathrm{~ns}$ \\
\hline & & $-0.45^{\star * *}$ & $0.09 \mathrm{~ns}$ & $-0.62^{\star \star \star}$ & $0.09 \mathrm{~ns}$ & $-0.67^{\star \star *}$ & $0.13 \mathrm{~ns}$ \\
\hline & $\overline{\mathrm{DL}}$ & $-0.67^{\star \star *}$ & $-0.31^{\star \star *}$ & $-0.57^{\star \star *}$ & $-0.27^{\star \star \star}$ & $-0.76^{* \star *}$ & $-0.15 \mathrm{~ns}$ \\
\hline & & $-0.59^{* * *}$ & $-0.08 \mathrm{~ns}$ & $-0.69^{* * *}$ & $-0.38^{* * *}$ & $-0.78^{* * *}$ & $-0.43^{\star * *}$ \\
\hline & & $-0.59^{* \star *}$ & $-0.13 \mathrm{~ns}$ & $-0.74^{\star \star *}$ & $-0.38^{* \star \star}$ & $-0.78^{* \star *}$ & $-0.37^{\star \star * *}$ \\
\hline & $\mathrm{BB}$ & $-0.10 \mathrm{~ns}$ & $-0.21^{* *}$ & $-0.35^{* * *}$ & $-0.10 \mathrm{~ns}$ & $-0.50^{* * *}$ & $-0.19^{\star *}$ \\
\hline & & $-0.43^{* * *}$ & $-0.18^{*}$ & $-0.55^{* * *}$ & $0.16 \mathrm{~ns}$ & $-0.53^{* * *}$ & $-0.06 \mathrm{~ns}$ \\
\hline & & $-0.53^{\star * *}$ & $0.01 \mathrm{~ns}$ & $-0.45^{\star * *}$ & $0.15 \mathrm{~ns}$ & $-0.67^{* * *}$ & $0.28^{* * *}$ \\
\hline & $\mathrm{BR}$ & $-0.07 \mathrm{~ns}$ & $-0.23^{* *}$ & $0.04 \mathrm{~ns}$ & $0.11 \mathrm{~ns}$ & $-0.17 \mathrm{~ns}$ & $0.11 \mathrm{~ns}$ \\
\hline & & $-0.06 \mathrm{~ns}$ & $-0.02 \mathrm{~ns}$ & $-0.18^{*}$ & $0.12 \mathrm{~ns}$ & $0.06 \mathrm{~ns}$ & $0.30^{* * *}$ \\
\hline & & $-0.37^{\star \star \star}$ & $-0.11 \mathrm{~ns}$ & $-0.34^{\star * *}$ & $0.09 \mathrm{~ns}$ & $-0.37^{* * *}$ & $-0.03 \mathrm{~ns}$ \\
\hline
\end{tabular}

SA: shoulder angle; muscles, TP: upper trapezius, DL: anterior deltoid, BB: biceps brachii, BR: brachioradialis. For each muscle, the three rows indicate, from higher to lower, the values for elbow angles $120^{\circ}, 90^{\circ}$, and $60^{\circ}$, respectively. *: $\mathrm{P}<0.05 ;{ }^{* *}$ : $\mathrm{P}<0.01$; ${ }^{* *}$ : $\mathrm{P}<0.001$; ns: not significant.

results showed a main significant effect of SA, \%MVC, and time on $\mathrm{RMS}_{\mathrm{MMG}}$ for all muscles. There was a significant main effect of EA on $\mathrm{RMS}_{\mathrm{MMG}}$ for DL and BR.

\section{RMS as a function of force}

Figure $4 \mathrm{~b}$ shows the relationship between $\mathrm{RMS}_{\mathrm{EMG}}$ and $\mathrm{RMS}_{\mathrm{MMG}}$ with the contraction levels of a typical muscle (BB). As expected, an increase in the isometric contraction level produces increasing $\mathrm{EMG}$ and $\mathrm{MMG}$ signal RMS values. At the onset of contraction and at exhaustion, the RMS amplitude of both EMG and MMG was almost linearly related to \%MVC. However, as Fig. 4b shows clearly, the differences between the onset and exhaustion values of EMG increased with increased \%MVC, while this kind of difference was not observed for the MMG signal. This behavior was noted for all four muscles. 
$20 \%$ MVC
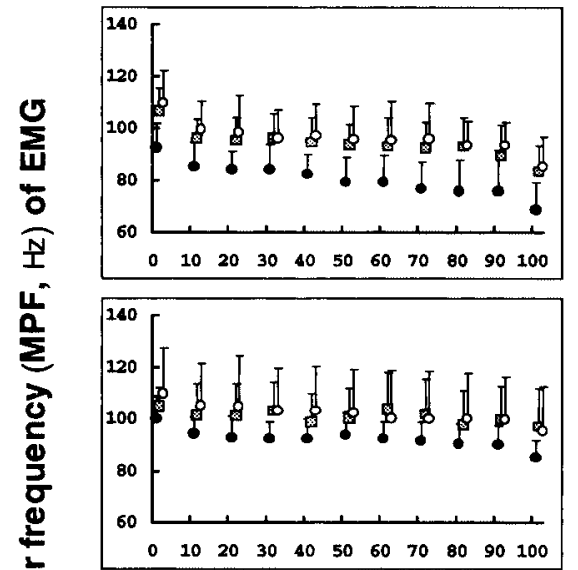

0
$\vdots$
0
$\Sigma$
0
0
0
$\Sigma$

EA:

- $120^{\circ}$
$40 \%$ MVC
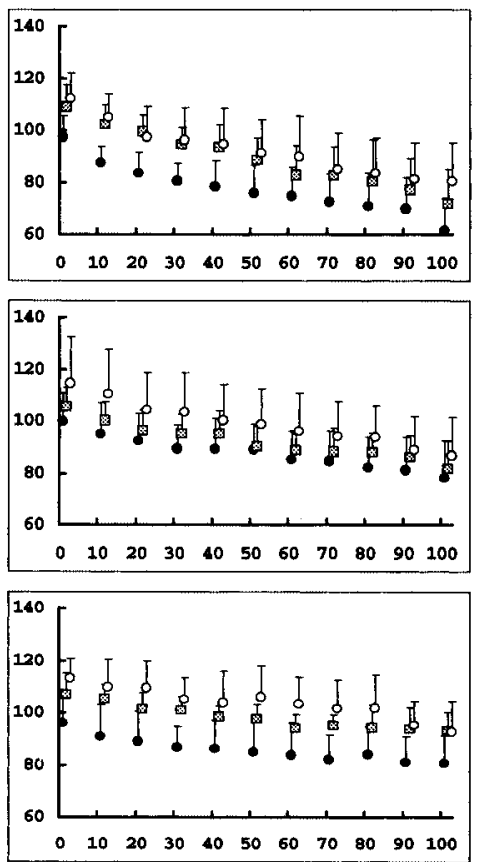

Time (\% endurance time)
$60 \%$ MVC
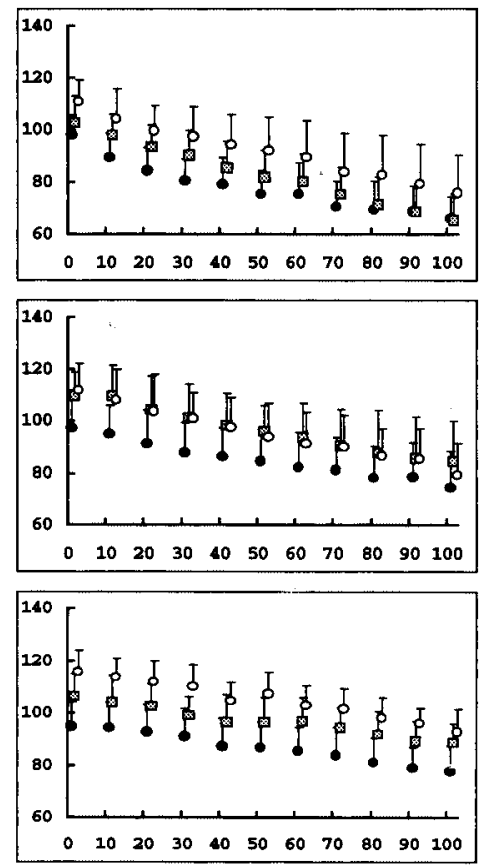

SA

$0^{\circ}$

$30^{\circ}$

$60^{\circ}$

Fig. 2 Changes in the electromyogram (EMG), mean power frequency (MPF) of biceps brachii muscle (BB) as a function of time (expressed as a percentage of the endurance time) during sustained isometric contraction under 27 experimental conditions. Each point is the average value (mean and $\mathrm{SD}, \mathrm{n}=10$ ) at the first second of each $10 \%$ of the endurance time. SA: shoulder angle; EA: elbow angle; MVC: maximum voluntary contraction.

\section{Discussion}

Although recent years have brought a renewed interest in the study of MMG, it is difficult, if not impossible, to compare results because of the diversity of experimental designs that have not employed well-known, reproducible, easy-to-measure physiological conditions or similar signal-processing techniques (Orizio et al., 1990). Previous articles (Rodriquez et al., 1996; Vaz et al., 1996) have suggested that the mechanism of muscle vibrations is not yet understood. The mechanism is complex but known, and it provides a basis for understanding experimental results. It is important to analyze both the frequency domain and the time domain in order to understand muscle contractile properties and their pathological conditions (Diemont et al., 1988; Esposito et al., 1996; Orizio et al., 1990; Wee and Ashley, 1989).

\section{Frequency domain analysis}

MPF of the EMG and MMG in this study were found to be within the same range as those reported for different muscles in our previous study (Koleini et al., 2001) and in studies by other investigators (Basmajian and De Luca, 1985; Nagata et al., 1990; Orizio et al., 1990; Pan et al.,
1989). As can be seen in Table 2 , the MMG frequency content is approximately two to three times lower than that of the EMG in all muscles. This distinct difference may reveal the difference in the underlying sources of the EMG and MMG signals. A possible explanation was suggested by Zhang et al. (1992). If the muscle fiber is cylindrical, shortening (contraction) could generate a radial expansion, resulting in vibration waves. Muscle fiber contraction is accompanied by the fiber's action potential. When muscle contraction increases, the firing rate and the number of recruited MUs increase following the size principle (Henneman et al., 1965). The EMG and MMG signals detected on the skin over the contracting muscle reflect a spatiotemporal summation of MU action potential and MU vibration signals, respectively. The shape differences between MU action potential and MU vibration signals are responsible for the differences in MPF reported in Table 2. This interpretation is supported by the simultaneous recording of MU action potential and MU vibration signal data obtained by electrical stimulation of the frog gastrocnemius muscle by Barry (1987) and Frangioni et al. (1987).

The results of the present investigation of all four muscles under all experimental conditions (except for BB 


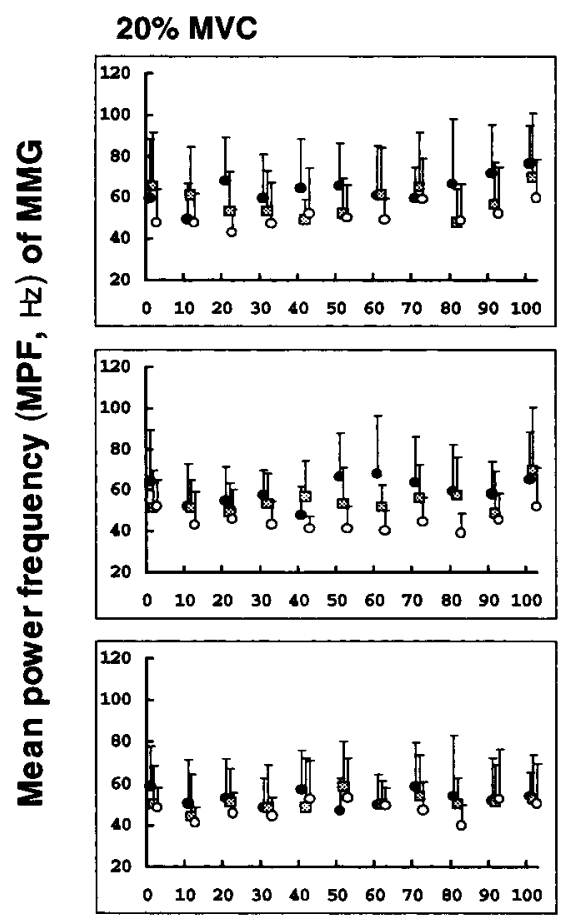

EA:

- $120^{\circ}$
$40 \%$ MVC
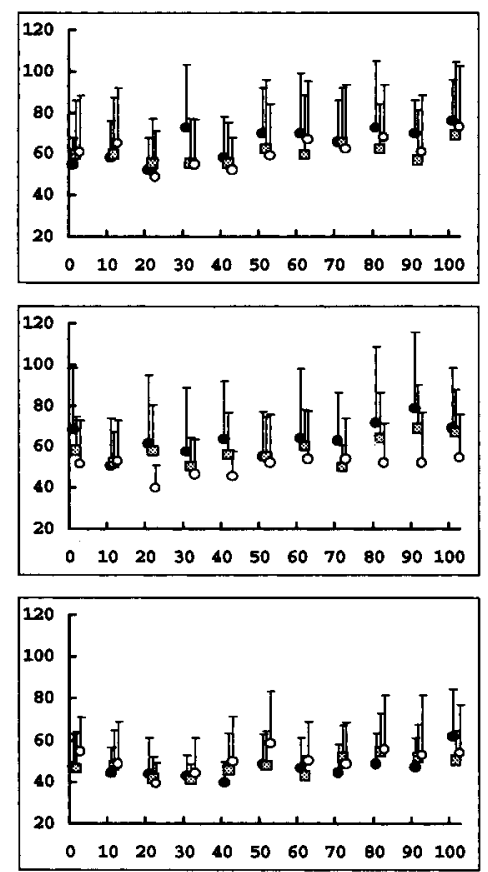

Time (\% endurance time)
$60 \%$ MVC

SA

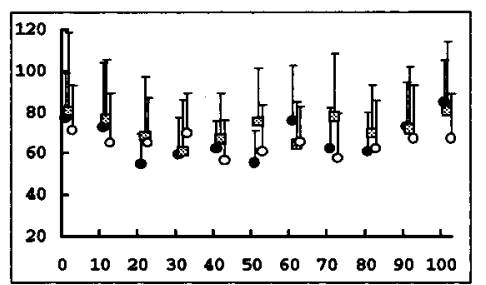

$0^{\circ}$

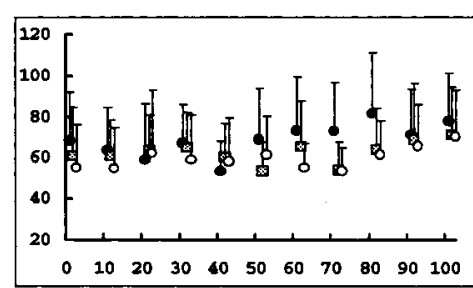

$30^{\circ}$

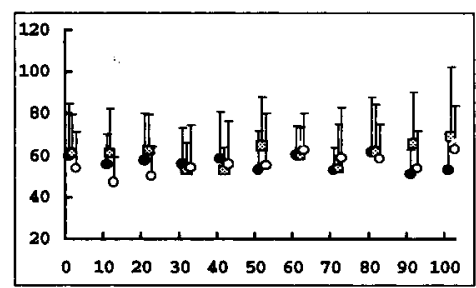

$60^{\circ}$

Fig. 3 Changes in the mechanomyogram (MMG), mean power frequency (MPF) of trapezius muscle (TP) as a function of time (expressed as a percentage of the endurance time) during sustained isometric contraction under 27 experimental conditions. Each point is the average value (mean and $\mathrm{SD}, \mathrm{n}=10$ ) at the first second of each $10 \%$ of the endurance time. SA: shoulder angle; EA: elbow angle; MVC: maximum voluntary contraction.

(a)

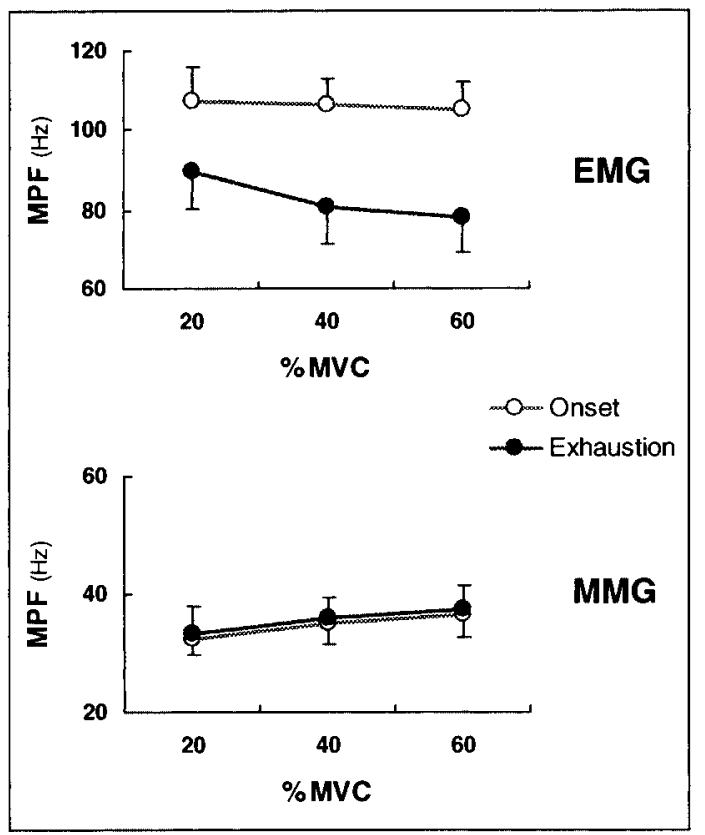

(b)

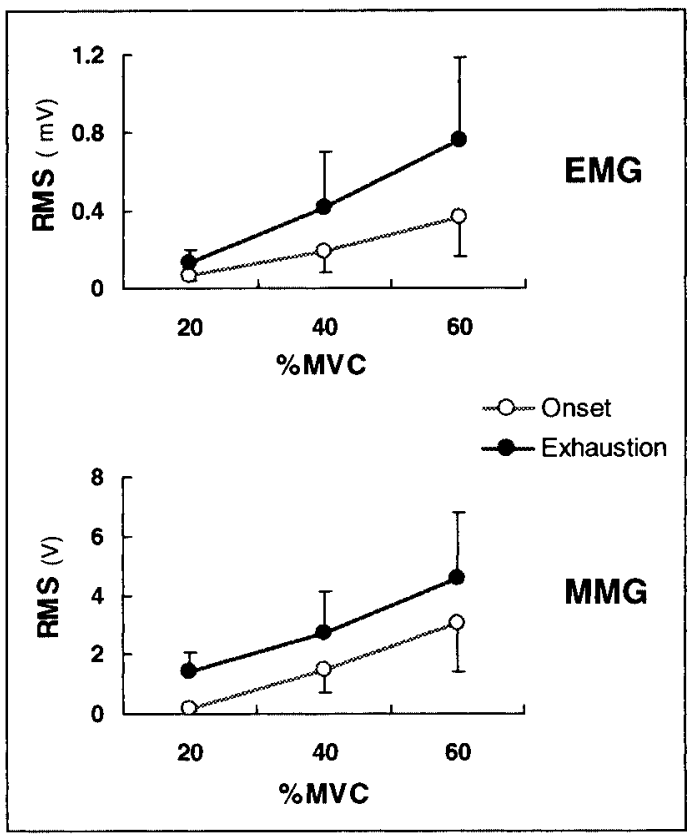

Fig. 4 Mean power frequency (MPF, a) and root mean square (RMS, b) of both electromyogram (EMG) and mechanomyogram (MMG) signals of typical muscle biceps brachii (BB) observed at the onset of contraction and at exhaustion, as a function of percent of maximal voluntary contraction (\%MVC). Values are mean and SD (averaged from each of 9 postures [3 shoulder angles $\times 3$ elbow angles], $n=10$ ). 
Table 4 Electromyogram (EMG, $\mathrm{mV}$ ) and mechanomyogram (MMG, V) root mean square (RMS) values (mean \pm $\mathrm{SD}$ ) of four muscles at onset and exhaustion of sustained isometric contractions (averaged from each of 9 postures, $\mathrm{n}=10$ )

\begin{tabular}{|c|c|c|c|c|c|c|c|}
\hline \multirow[b]{2}{*}{ RMS } & \multirow[b]{2}{*}{ Muscle } & \multicolumn{2}{|c|}{$20 \% \mathrm{MVC}$} & \multicolumn{2}{|c|}{$40 \% \mathrm{MVC}$} & \multicolumn{2}{|c|}{$60 \% \mathrm{MVC}$} \\
\hline & & Onset & Exhaustion & Onset & Exhaustion & Onset & Exhaustion \\
\hline \multirow[t]{4}{*}{ EMG } & $\mathrm{TP}$ & $0.03 \pm 0.03$ & $0.07 \pm 0.04$ & $0.06 \pm 0.05$ & $0.13 \pm 0.06$ & $0.11 \pm 0.06$ & $0.31 \pm 0.10$ \\
\hline & DL & $0.10 \pm 0.04$ & $0.23 \pm 0.09$ & $0.35 \pm 0.11$ & $0.84 \pm 0.43$ & $0.63 \pm 0.20$ & $1.32 \pm 0.58$ \\
\hline & $\mathrm{BB}$ & $0.07 \pm 0.08$ & $0.16 \pm 0.16$ & $0.22 \pm 0.13$ & $0.49 \pm 0.21$ & $0.45 \pm 0.21$ & $1.00 \pm 0.36$ \\
\hline & $\mathrm{BR}$ & $0.05 \pm 0.06$ & $0.09 \pm 0.12$ & $0.13 \pm 0.15$ & $0.20 \pm 0.21$ & $0.26 \pm 0.24$ & $0.40 \pm 0.30$ \\
\hline \multirow[t]{4}{*}{ MMG } & $\mathrm{TP}$ & $0.10 \pm 0.06$ & $0.55 \pm 0.14$ & $0.48 \pm 0.10$ & $0.83 \pm 0.18$ & $0.91 \pm 0.24$ & $1.56 \pm 0.79$ \\
\hline & DL & $0.12 \pm 0.06$ & $1.04 \pm 0.23$ & $0.96 \pm 0.35$ & $1.72 \pm 0.56$ & $2.07 \pm 0.81$ & $3.29 \pm 1.68$ \\
\hline & $\mathrm{BB}$ & $0.28 \pm 0.09$ & $2.29 \pm 0.73$ & $2.42 \pm 1.01$ & $4.07 \pm 2.08$ & $4.84 \pm 2.29$ & $6.82 \pm 3.85$ \\
\hline & $\mathrm{BR}$ & $0.23 \pm 0.12$ & $1.74 \pm 0.43$ & $1.95 \pm 0.94$ & $4.18 \pm 1.95$ & $4.38 \pm 2.20$ & $6.64 \pm 3.77$ \\
\hline
\end{tabular}

The muscles, TP: upper trapezius, DL: anterior deltoid, BB: biceps brachii, BR: brachioradialis.

at $\mathrm{SA} 30^{\circ}-\mathrm{EA} 60^{\circ}-40 \% \mathrm{MVC}, \mathrm{SA} 60^{\circ}-\mathrm{EA} 120^{\circ}-40 \% \mathrm{MVC}$, and $\mathrm{SA} 60^{\circ}-\mathrm{EA} 90^{\circ}-60 \% \mathrm{MVC}$ ) indicate that the $\mathrm{MPF}_{\mathrm{EMG}}$ signal tended to decrease continuously throughout the sustained isometric contraction, and that it is associated with a loss of the high-frequency contents of the signal (Fig. 2), whereas the corresponding $\mathrm{MPF}_{\mathrm{MMG}}$ signal typically remained about constant (Fig. 3). During sustained isometric contraction, the EMG signal showed the well-known shift to lower frequencies. The principal reason for this shift is the lowering of the muscle fiber conduction velocity, and central factors such as synchronization could also play a role (Zwarts et al., 1987).

In contrast, the $\mathrm{MPF}_{\mathrm{MMG}}$ did not shift throughout the test contractions, although the form of MMG spectra changed. The factor of muscle stiffness could be the basis of one of the physiological hypotheses to explain this behavior of MMG frequency over time. The resonant frequency of muscle is a function of several parameters, including muscle mass, length, topology, and stiffness. During an isometric contraction, the change in stiffness is much greater than the change in any of the other parameters. This implies that the change in resonant frequency should be closely related to the change in stiffness during isometric contraction (Barry and Cole, 1990). In our experiment, force was constant (as \%MVC) during test contraction. Since muscle vibrations appear to occur at the resonant frequency of the muscle, the $\mathrm{MPF}_{\mathrm{MMG}}$ signal tends to remain roughly constant throughout sustained isometric contraction. MMG frequency changes found over time in the present study were in agreement with those reported in the literature by Herzog et al. (1994) and Koleini et al. (2001).

\section{Time domain analysis}

The EMG amplitude changes found during sustained isometric contraction are well known from the literature. In the present study, increased $\mathrm{RMS}_{\mathrm{EMG}}$ from the beginning to the end of the test was found (Fig. 5) for all muscles under all experimental conditions (except for DL at $\mathrm{SA} 0^{\circ}-\mathrm{EA} 120^{\circ}-40 \% \mathrm{MVC}$ ). Our findings were in good agreement with previous investigations (De Luca, 1984; Moritani et al., 1986). The increase in $\mathrm{RMS}_{\mathrm{EMG}}$ is due to an increase in the firing rate and recruitment of MUs (Freund, 1983).

MMG amplitude has shown to reflect many factors. Orizio (1993) suggested that the MMG amplitude may also be affected by factors such as muscle architecture and the properties of the tissue layers between the muscle and the MMG recording device on the skin's surface. It has been suggested that, during sustained low-level isometric contraction, MMG amplitude increases slowly as fatigue proceeds, and during high-level contraction MMG amplitude shows either a lack of increase or a decrease (Goldenberg et al., 1991; Orizio et al., 1989a; Rodriquez et al., 1993). The response seen in the MMG during low-level contractions could be attributed to the recruitment of new MUs and to an increase in MU firing rate. The MMG responses seen during high-level contractions would result from the recruitment of fast MUs and a reduction in the MU firing rate (Orizio, 1993). This may reflect force-dependent differences in the fatigue process at differing levels of contraction. Generally, it is accepted that only the type I (slow-twitch) fibers are active at 20\% MVC (Burke, 1981; Freund, 1983), while at high contraction levels, when both type I and type II (fast-twitch) fibers are activated, the MMG is affected by the individual muscular fiber composition (Diemont et al., 1988). As can be seen in Fig. 6, our investigation also found this change in MMG amplitude. In the test at $20 \% \mathrm{MVC}$, the $\mathrm{RMS}_{\mathrm{MMG}}$ increased monotonically up to exhaustion. At 40\% MVC, RMS increased at varying rates during low-level contraction. The test at 60\% MVC demonstrated no unequivocal trend in the amplitude (fluctuation form), namely, a progressive increase in power followed by decreases thereafter. This finding supports the hypothesis (Barry et al., 1985) that the RMS amplitude of the MMG signal 
Table 5 Pearson correlation coefficient between time of contraction and root mean square (RMS) values of electromyogram (EMG) and mechanomyogram (MMG) signals of four muscles during sustained isometric contractions under 27 experimental conditions $(n=10)$

\begin{tabular}{|c|c|c|c|c|c|c|c|}
\hline \multirow[b]{2}{*}{$\mathrm{SA}$} & \multirow[b]{2}{*}{ Muscle } & \multicolumn{2}{|c|}{$20 \% \mathrm{MVC}$} & \multicolumn{2}{|c|}{$40 \% \mathrm{MVC}$} & \multicolumn{2}{|c|}{$60 \% \mathrm{MVC}$} \\
\hline & & EMG & MMG & EMG & MMG & EMG & MMG \\
\hline \multirow[t]{12}{*}{$0^{\circ}$} & $\mathrm{TP}$ & $0.34^{* * *}$ & $0.79^{* \star *}$ & $0.35^{* * *}$ & $0.22^{\star \star}$ & $0.45^{* \star *}$ & $0.09 \mathrm{~ns}$ \\
\hline & & $0.57^{* * *}$ & $0.60^{* * *}$ & $0.24^{* \star}$ & $0.39^{* * *}$ & $0.53^{* * *}$ & $0.14 \mathrm{~ns}$ \\
\hline & & $0.44^{* * *}$ & $0.67^{\star \star *}$ & $0.43^{\star \star \star}$ & $0.43^{\star \star \star}$ & $0.20^{* *}$ & $0.17 \mathrm{~ns}$ \\
\hline & $\overline{\mathrm{DL}}$ & $0.06 \mathrm{~ns}$ & $0.72^{\star \star \star}$ & $-0.17 \mathrm{~ns}$ & $0.26^{\star \star \star}$ & $0.03 \mathrm{~ns}$ & $-0.09 \mathrm{~ns}$ \\
\hline & & $0.27^{* * *}$ & $0.60^{* * *}$ & $0.20^{*}$ & $0.38^{* * *}$ & $0.30^{* * *}$ & $0.05 \mathrm{~ns}$ \\
\hline & & $0.27^{\star *}$ & $0.70^{\star \star \star}$ & $0.18^{*}$ & $0.36^{\star * *}$ & $0.27^{\star \star}$ & $0.13 \mathrm{~ns}$ \\
\hline & $\mathrm{BB}$ & $0.59^{* \star \star}$ & $0.78^{\star \star \star}$ & $0.32^{* \star *}$ & $-0.08 \mathrm{~ns}$ & $0.32^{* * *}$ & $-0.44^{* * \star}$ \\
\hline & & $0.37^{* * *}$ & $0.68^{* * *}$ & $0.46^{\text {***}}$ & $0.25^{* *}$ & $0.51^{* * *}$ & $-0.17^{\star}$ \\
\hline & & $0.30^{* * *}$ & $0.68^{\star \star \star}$ & $0.31^{\text {*** }}$ & $0.24^{\star \star}$ & $0.30^{\star \star *}$ & $0.04 \mathrm{~ns}$ \\
\hline & $\mathrm{BR}$ & $0.57^{* * *}$ & $0.84^{\star \star *}$ & $0.41^{\star \star *}$ & $0.11 \mathrm{~ns}$ & $0.29^{\star \star \star}$ & $-0.38^{* * *}$ \\
\hline & & $0.41^{* * *}$ & $0.71^{* * *}$ & $0.54^{* \star *}$ & $0.47^{* * *}$ & $0.25^{* *}$ & $-0.08 \mathrm{~ns}$ \\
\hline & & $0.35^{\star * *}$ & $0.77^{\star \star \star}$ & $0.23^{* \star}$ & $0.50^{* * *}$ & $0.07 \mathrm{~ns}$ & $0.25^{\star \star}$ \\
\hline \multirow[t]{12}{*}{$30^{\circ}$} & $\mathrm{TP}$ & $0.47^{* * *}$ & $0.48^{\star * *}$ & $0.34^{* * *}$ & $0.24^{* *}$ & $0.38^{\star * *}$ & $-0.01 \mathrm{~ns}$ \\
\hline & & $0.59^{* * *}$ & $0.56^{\star \star \star}$ & $0.33^{* * *}$ & $0.20^{\star *}$ & $0.57^{\star \star *}$ & $0.02 \mathrm{~ns}$ \\
\hline & & $0.45^{* * *}$ & $0.55^{* * *}$ & $0.33^{* * *}$ & $0.38^{* * *}$ & $0.33^{* * *}$ & $0.29^{\star \star *}$ \\
\hline & $\overline{\mathrm{DL}}$ & $0.28^{* * *}$ & $0.52^{\star * *}$ & $0.36^{* \star *}$ & $0.35^{\star \star *}$ & $0.26^{\star \star *}$ & $0.02 \mathrm{~ns}$ \\
\hline & & $0.41^{* * *}$ & $0.54^{\star \star \star}$ & $0.34^{* * *}$ & $0.11 \mathrm{~ns}$ & $0.28^{\star \star *}$ & $-0.03 \mathrm{~ns}$ \\
\hline & & $0.42^{* * *}$ & $0.57^{* * *}$ & $0.46^{* \star *}$ & $0.31^{* * *}$ & $0.39^{\star * *}$ & $0.14 \mathrm{~ns}$ \\
\hline & $\mathrm{BB}$ & $0.30^{* * *}$ & $0.57^{\star \star *}$ & $0.28^{* * *}$ & $0.20^{* *}$ & $0.27^{\star \star *}$ & $-0.09 \mathrm{~ns}$ \\
\hline & & $0.29^{* \star *}$ & $0.65^{\star \star *}$ & $0.21^{\star *}$ & $0.06 \mathrm{~ns}$ & $0.15 \mathrm{~ns}$ & $0.05 \mathrm{~ns}$ \\
\hline & & $0.37^{* * *}$ & $0.61^{* * *}$ & $0.45^{\text {*** }}$ & $0.40^{* * *}$ & $0.40^{* * *}$ & $0.17^{\star}$ \\
\hline & $\overline{B R}$ & $0.38^{* * *}$ & $0.53^{* * *}$ & $0.20^{* *}$ & $0.31^{* \star *}$ & $0.14 \mathrm{~ns}$ & $0.03 \mathrm{~ns}$ \\
\hline & & $0.42^{* * *}$ & $0.67^{\star * *}$ & $0.15 \mathrm{~ns}$ & $0.29^{\star \star \star}$ & $0.18^{*}$ & $0.11 \mathrm{~ns}$ \\
\hline & & $0.40^{* * *}$ & $0.63^{* * *}$ & $0.49^{* \star *}$ & $0.47^{\text {***}}$ & $0.41^{* * *}$ & $0.27^{* \star *}$ \\
\hline \multirow[t]{12}{*}{$60^{\circ}$} & $\mathrm{TP}$ & $0.15 \mathrm{~ns}$ & $0.54^{\star * *}$ & $0.35^{\star * \star}$ & $0.08 \mathrm{~ns}$ & $0.46^{\star * \star}$ & $0.20^{* *}$ \\
\hline & & $0.43^{* * *}$ & $0.45^{* * *}$ & $0.44^{* \star *}$ & $0.26^{* * *}$ & $0.48^{* * *}$ & $0.24^{* *}$ \\
\hline & & $0.33^{* * *}$ & $0.61^{\text {***}}$ & $0.48^{\star \star *}$ & $0.16 \mathrm{~ns}$ & $0.49^{\text {***}}$ & $-0.06 \mathrm{~ns}$ \\
\hline & $\mathrm{DL}$ & $0.24^{\star *}$ & $0.50^{* * *}$ & $0.32^{\star \star *}$ & $0.10 \mathrm{~ns}$ & $0.40^{* * *}$ & $0.21^{* \star}$ \\
\hline & & $0.29^{* * *}$ & $0.48^{\star \star *}$ & $0.34^{* * *}$ & $0.23^{* *}$ & $0.42^{\star \star \star}$ & $0.24^{\star *}$ \\
\hline & & $0.46^{* * *}$ & $0.55^{\star \star *}$ & $0.52^{* \star *}$ & $0.07 \mathrm{~ns}$ & $0.39^{\star * *}$ & $-0.17^{\star}$ \\
\hline & $\mathrm{BB}$ & $0.21^{* *}$ & $0.60^{* * *}$ & $0.21^{\star *}$ & $0.32^{\star * *}$ & $0.27^{* \star *}$ & $0.32^{* * *}$ \\
\hline & & $0.53^{* * *}$ & $0.48^{* * *}$ & $0.24^{* *}$ & $0.33^{* * *}$ & $0.15 \mathrm{~ns}$ & $0.23^{* *}$ \\
\hline & & $0.44^{* * *}$ & $0.47^{\star * *}$ & $0.58^{* * *}$ & $0.10 \mathrm{~ns}$ & $0.44^{* * *}$ & $-0.20^{\star \star}$ \\
\hline & $\mathrm{BR}$ & $0.17 \mathrm{~ns}$ & $0.53^{* * *}$ & $0.02 \mathrm{~ns}$ & $0.18^{*}$ & $0.13 \mathrm{~ns}$ & $0.27^{\star * *}$ \\
\hline & & $0.35^{* * *}$ & $0.38^{\star * *}$ & $0.63^{* * *}$ & $0.31^{* * *}$ & $0.24^{\star *}$ & $0.30^{* * *}$ \\
\hline & & $0.47^{* * *}$ & $0.54^{\star \star \star}$ & $0.33^{* * *}$ & $0.40^{* * *}$ & $0.40^{\star \star *}$ & $0.14 \mathrm{~ns}$ \\
\hline
\end{tabular}

SA: shoulder angle; muscles, TP: upper trapezius, DL: anterior deltoid, BB: biceps brachii, BR: brachioradialis. For each muscle, the three rows indicate, from higher to lower, the values for elbow angles $120^{\circ}, 90^{\circ}$, and $60^{\circ}$, respectively. ${ }^{*}$ : $\mathrm{P}<0.05$; ${ }^{* *}$ : $\mathrm{P}<0.01$; ${ }^{* *}$ : $\mathrm{P}<0.001$; ns: not significant.

produced during skeletal muscle contraction is highly correlated with force production.

\section{$E M G$ and $M M G$ signal changes with force}

Fewer data are available regarding MMG frequency characteristics and force, but MPF has also shown to increase with increases in force production (Dalton and Stokes, 1993; Matheson et al., 1997; Maton et al., 1990; Orizio et al., 1990). Except for DL at the onset of contraction, the results of the present study for $\mathrm{TP}, \mathrm{BB}$, and BR were consistent with those of previous investigations reporting that kind of relationship. Orizio et al. (1990) clearly demonstrated the relationship between MMG frequency content vs. force in biceps brachii muscle. They showed that increasing the intensity of muscle contraction resulted in the enlargement of the MMG spectrum that is, shifts to higher frequencies with increases in intensity as might be the 
$20 \%$ MVC

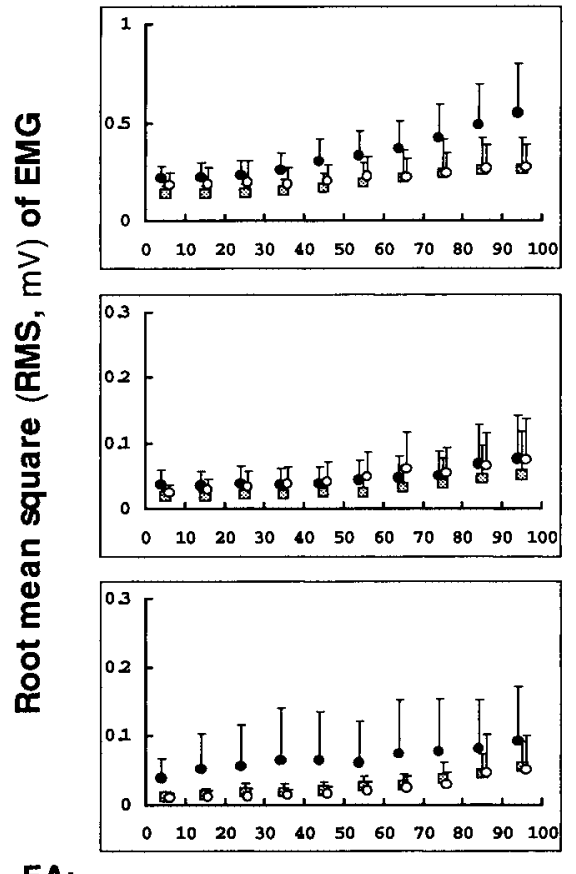

EA:

- $120^{\circ}$ 口 $90^{\circ} \circ 60^{\circ}$
$40 \%$ MVC
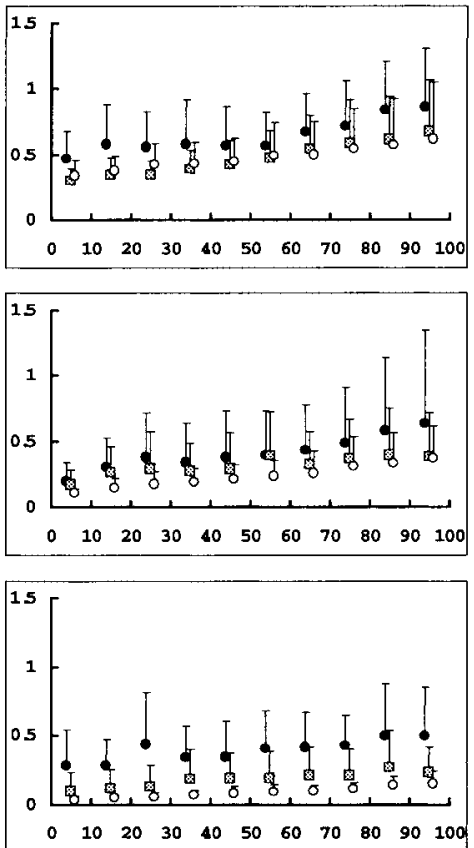

Time (\% endurance time)
$60 \%$ MVC

SA

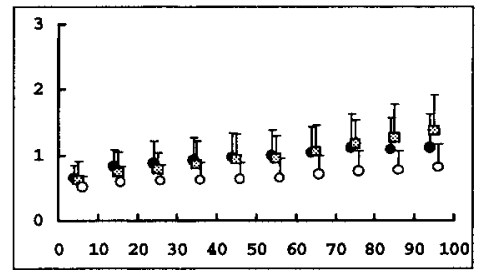

$0^{\circ}$

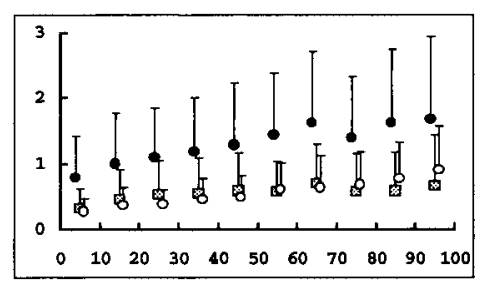

$30^{\circ}$

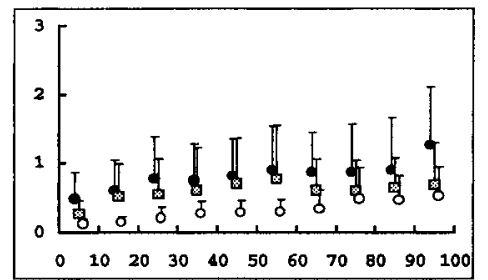

$60^{\circ}$

Fig. 5 Changes in the electromyogram (EMG), root mean square (RMS) of biceps brachii muscle (BB) as a function of time (expressed as a percentage of the endurance time) during sustained isometric contraction under 27 experimental conditions. Each point is the average value (mean and SD, $\mathrm{n}=10$ ) for the period of $10 \%$ of the endurance time. SA: shoulder angle; EA: elbow angle; MVC: maximum voluntary contraction.

case with a greater contribution by type II fibers with increasing force generation (Mealing and McCarthy, 1991). Moreover, these force-dependent $\mathrm{MPF}_{\mathrm{MMG}}$ changes have been suggested to reflect the firing rate of MUs (Shinohara et al., 1998). It has been suggested that increased $\mathrm{MPF}_{\mathrm{MMG}}$ with increased firing rate may have been due to increased muscle stiffness associated with increased firing rate (Vaz et al., 1997).

The increase in the amplitudes of the EMG and MMG signals accompanying increased contraction force was previously attributed to increased temporal and spatial recruitment (Dalton and Stokes, 1993; De Luca, 1984). It was previously postulated that EMG amplitude is affected by recruitment of additional MUs, firing rate, muscle architecture, and muscle fiber conduction velocity (De Luca, 1984). Factors affecting the MMG signal amplitude are less clear. As the contracting muscle becomes fatigued, the increase in signal strength with increasing force suggests that MMG amplitude reflects MU recruitment, although it is unclear how much firing rates, recruitment of new MUs, tremor, or mechanical factors contribute to the increase (Bolton et al., 1989; Dalton and Stokes, 1993).

Several studies have examined the relationship between MMG amplitude and \%MVC. At least for contractions of up to $80 \% \mathrm{MVC}$, it has been found that MMG amplitude increases with increased force (Orizio et al., 1989b, 1990). This relationship was found to be linear in the quadriceps (Stokes and Dalton, 1991a), quadratic in the lumbar erector spinae (Stokes et al., 1988), and curvilinear in the adductor pollicis (Stokes and Cooper, 1992). Orizio (1993) and Stokes and Dalton (1991a) suggested that these non-uniform relationships were due largely to the differences in the composition and contractile properties of muscle fibers. In the present study, we observed increases of $\mathrm{RMS}_{\mathrm{MMG}}$ from $20 \%$ to $60 \%$ MVC for all four muscles. Our results on MMG amplitude are in good agreement with previous investigations.

\section{Dependence on joint angle}

In this study, sustained contraction was performed up to exhaustion at three SA and three EA. As can be seen in Table 1, at three different levels of contraction endurance was briefest at $\mathrm{SA} 60^{\circ}-\mathrm{EA} 120^{\circ}$ (except for $60 \% \mathrm{MVC}$ at EA $90^{\circ}$ ). Furthermore, the smallest MVC also occurred at this posture. These results showed that the shortest endurance time occurred at the longest muscle length of BB and BR. Previous studies (Caldwell, 1963; Petrofsky and Phillips, 1980) indicate that endurance time in elbow flexion is not dependent on the elbow angle. Our data 


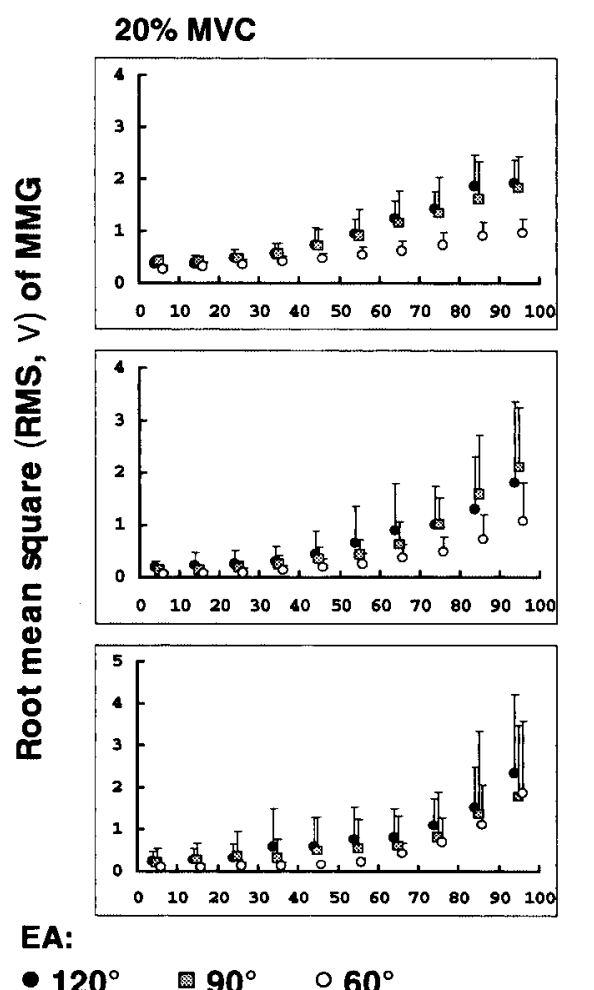

$40 \%$ MVC
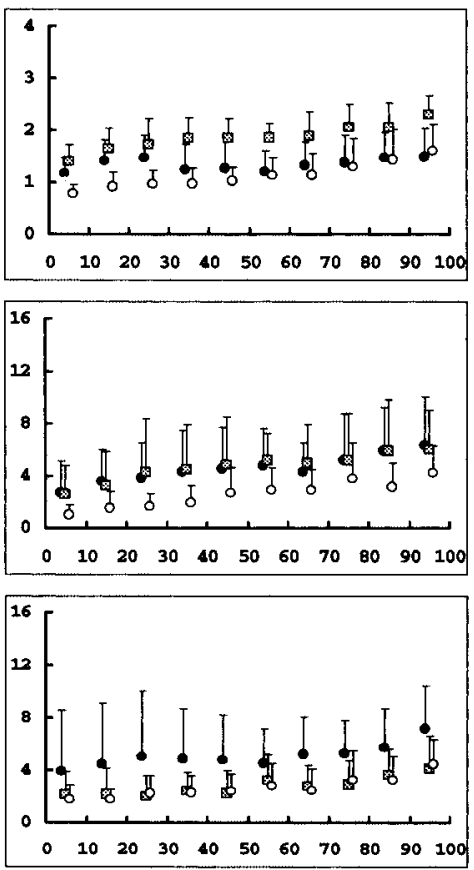

Time (\% endurance time)
$60 \%$ MVC

SA

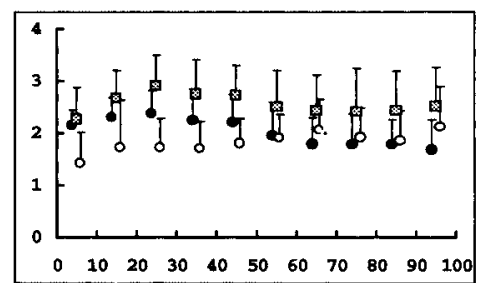

$0^{\circ}$

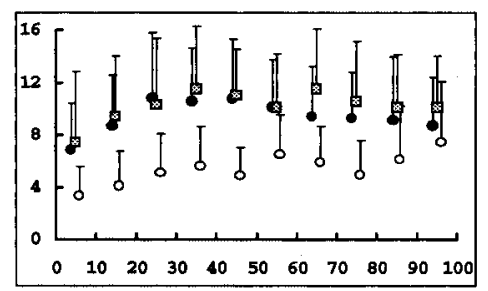

$30^{\circ}$

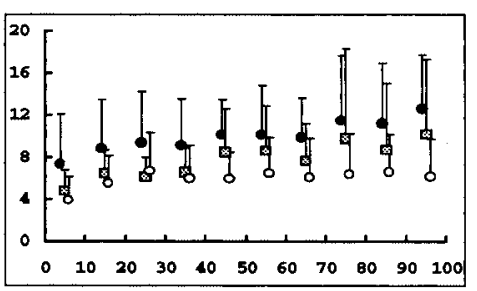

$60^{\circ}$

Fig. 6 Changes in the mechanomyogram (MMG), root mean square (RMS) of brachioradialis muscle (BR) as a function of time (expressed as a percentage of the endurance time) during sustained isometric contraction under 27 experimental conditions. Each point is the average value (mean and $\mathrm{SD}, \mathrm{n}=10$ ) for the period of $10 \%$ of the endurance time. SA: shoulder angle; EA: elbow angle; MVC: maximum voluntary contraction.

support this previous finding, but in contrast to EA, SA showed a highly significant $(p<0.0001)$ main effect on endurance time for all postures.

Several studies have shown that muscle length affects the rate of muscle fatigue, based on the rate of force loss (Fitch and McComas, 1985; Sacco et al., 1994) as well as on the rate of changes in the EMG signal (Doud and Walsh, 1995; Weir et al., 1996) and MMG signal (Weir et al., 2000). This study has also noted a dependence of MPF and RMS values of the EMG and MMG signals on joint angles. It is interesting to note that for TP and DL, the largest rate of decrease of $\mathrm{MPF}_{\mathrm{EMG}}$ occurred at $\mathrm{SA} 60^{\circ}-$ EA $60^{\circ}$ with change ratios of $-27 \%$ and $-37 \%$, and that the smallest rate of decrease occurred at $\mathrm{SA} 0^{\circ}-\mathrm{EA} 60^{\circ}, \mathrm{SA} 0^{\circ}-$ EA $120^{\circ}$ with change ratios of $-11 \%$ and $-14 \%$, respectively. On the other hand, for $\mathrm{BB}$ and $\mathrm{BR}$ the largest rate of decreases were at $\mathrm{SA} 0^{\circ}-\mathrm{EA} 120^{\circ}$ with change ratios of $-37 \%$ and $-25 \%$, and the smallest rate of decreases were at $\mathrm{SA} 30^{\circ}-\mathrm{EA} 90^{\circ}, \mathrm{SA} 60^{\circ}-\mathrm{EA} 90^{\circ}$ with change ratios of $-7 \%$ and $-4 \%$, respectively. This clearly indicates that the most important muscles during flexion at the shoulder joint are TP and DL, while the most important muscles during flexion at the elbow joint are $\mathrm{BB}$ and $\mathrm{BR}$. With regard to the results of the present investigation, the largest rate of increase of $\mathrm{RMS}_{\mathrm{MMG}}$ values (which was found at 20\% MVC), occurred at the muscle length corresponding to $\mathrm{SA} 60^{\circ}-\mathrm{EA} 60^{\circ}$ for $\mathrm{TP}, \mathrm{DL}$, and BR (1884\%, 3746\%, 2672\%), and for BB at SA60 ${ }^{\circ}$ EA $120^{\circ}$ (2525\%), respectively. The ANOVA results also revealed the main effect of $\mathrm{SA}$ on changes of $\mathrm{RMS}_{\mathrm{MMG}}$ for all four muscles. Moreover, at $\mathrm{SA} 60^{\circ}$ the maximum values of $\mathrm{RMS}_{\mathrm{MMG}}$ found for TP, $\mathrm{DL}, \mathrm{BB}$, and $\mathrm{BR}$ were 3.4 $\mathrm{V}, 6.2 \mathrm{~V}, 11.7 \mathrm{~V}$, and $12.6 \mathrm{~V}$, respectively. It appears that muscle located far from the shoulder joint has a higher $\mathrm{RMS}_{\mathrm{MMG}}$ value than muscle closer to the joint.

The Borg scale is a recognized and widely used method for measuring subjective estimates of fatigue (Borg, 1982). We assessed the Borg scale values and calculated the time constant of values in order to produce an index that was comparable with other parameters. The results of the current study indicate that the time constant is directly related to SA. In other words, the feeling of fatigue occurred slowly with increased SA. This effect of SA on the time constant was also found to be highly significant. It can be seen in Fig. 1 that the effect of three different EA on Borg scale values was not so considerable. Statistical analysis also showed no significant effect of EA on this parameter. 


\section{Conclusion}

We have examined the simultaneous MMG and EMG signals during sustained isometric contraction. MPF, RMS, and \%MVC relationships of the MMG and those of the EMG described the basic muscle activation patterns. The present results obtained from both signals combined confirm and extend previous reports on the contractile properties of muscles. The differences in frequency content between the MMG and EMG indicate the shape differences of waveform between the mechanical and electrical responses to muscle. However, since there are some fundamental differences between the MMG and EMG signals from muscle, we would emphasize the need for more research to clarify and better understand the phenomenon of vibratory signal emission from contracting muscle. An additional aim of the current study was to assess the effect of joint angle on MMG and EMG. We have found clear significant relationships between the signal parameters and both SA and EA. In particular, in BB an increase in the EA (or muscle length) produces a) decreasing $\mathrm{MPF}_{\mathrm{EMG}}$ values at all experimental conditions and b) increasing RMS of both EMG (at all conditions) and MMG signals (only at 20\% MVC tests). Furthermore, a significant relationship was also found between SA and subjective evaluation. These results support the findings of our group's previous study (Koleini et al. 2001).

\section{References}

Akataki K, Mita K, Itoh Y, Suzuki N, Watanabe M (1996) Acoustic and electrical activities during voluntary isometric contraction of biceps brachii muscle in patients with spastic cerebral palsy. Muscle Nerve 19: $1252-1257$

Barry DT (1987) Acoustic signals from frog skeletal muscle. Biophys J 51: 769-773

Barry DT (1991) Muscle sounds from evoked twitches in the hand. Arch Phys Med Rehabil 72: 573-575

Barry DT (1992) Vibrations and sounds from evoked muscle twitches. Electromyogr Clin Neurophysiol 32: $35-40$

Barry DT, Cole NM (1990) Muscle sounds are emitted at the resonant frequencies of skeletal muscle. IEEE Trans Biomed Eng 37: 525-531

Barry DT, Geiringer SR, Ball RD (1985) Acoustic myography: a noninvasive monitor of motor unit fatigue. Muscle Nerve 8: 189-194

Basmajian JV, De Luca CJ (1985) Muscles Alive. In Butler $\mathrm{J}$ ed. Their functions revealed by electromyography. Williams and Wilkins Waverly Press, Baltimore, Md

Bolton CF, Parkes A, Thompson TR, Clark MR, Sterne CJ (1989) Recording sound from human skeletal muscle: technical and physiological aspects. Muscle Nerve 12:
$126-134$

Borg G (1982) A category scale with ratio properties for intermodal and interindividual comparisons. In Geissler HG, Petzold P eds. Psychophysical judgement and the process of perception, Berlin, VEB, 25-34

Borg G (1990) Psychophysical scaling with applications in physical work and the perception of exertion. Scand J Work Envir Health 16: 55-58

Burke RE (1981) Motor units: anatomy physiology and functional organization. In Brooks VB ed. Handbook of physiology. Sect I, Vol 2, The nervous system: motor control, Part I, Bethesda APS, 345-422

Caldwell LS (1963) Relative muscle loading and endurance. J Eng Psychol 2: 155-161

Caldwell LS, Chaffin DB, Dukes-Dobos FN, Kroemer KHE, Laubach LL, Snook SH, Wasserman DE (1974) A proposed standard procedure for static muscle strength testing. Am Ind Hyg Assoc J 35: 201-206

Dalton PA, Stokes MJ (1993) Frequency of acoustic myography during isometric contraction of fresh and fatigued muscle and during dynamic contractions. Muscle Nerve 16: 255-261

De Luca CJ (1984) Myoelectrical manifestations of localized muscular fatigue in humans. Crit Rev Biomed Eng 11(4): 251-279

De Luca CJ (1979) Physiology and mathematics of myoelectric signals. IEEE Trans Biomed Eng, Vol BME26: 313-325

Diemont B, Maranzana Figini M, Orizio C, Perini R, Veicsteinas A (1988) Spectral analysis of muscular sound at low and high contraction level. Int J Biomed Comput 23: 161-175

Doud JR, Walsh JM (1995) Muscle fatigue and muscle length interaction: effect on the EMG frequency components. Electromyogr Clin Neurophysiol 35: 331339

Esposito F, Malgrati D, Veicsteinas A, Orizio C (1996) Time and frequency domain analysis of electromyogram and sound myogram in the elderly. Eur J Appl Physiol 73: 503-510

Fitch S, McComas A (1985) Influence of human muscle length on fatigue. J Physiol (lond) 362: 205-213

Frangioni JV, Kwan-Gett TS, Dobrunz LE, McMahon TA (1987) The mechanism of low-frequency sound production in muscle. Biophys J 51: 775-783

Freund HJ (1983) Motor unit and muscle activity in voluntary motor control. Physiol Rev 63: 387-436

Goldenberg MS, Yack HJ, Cerny FJ, Burton HW (1991) Acoustic myography as an indicator of force during sustained contractions of a small hand muscle. J Appl Physiol 70: 87-91

Gordon G, Holbourn AHS (1948) The sounds from single motor units in a contracting muscle. J Physiol 107: 456-464

Henneman E, Somjen G, Carpenter D (1965) Functional 
significance of cell size in spinal motor neurons. J Neurophysiol 28: 560-580

Herzog W, Zhang YT, Vaz MA, Guimaraes ACS, Janssen C (1994) Assessment of muscular fatigue using vibromyography. Muscle Nerve 17: 1156-1161

Kankaanpää M, Taimela S, Webber CL, Airaksinen O, Hanninen O (1997) Lumbar paraspinal muscle fatiguability in repetitive isoinertial loading: EMG spectral indices, Borg scale and endurance time. Eur J Appl Physiol 76: 236-242

Keidel M, Keidel WD (1989) The computervibromyography as a biometric progress in studying muscle function. Biomedizische Technik 34: 107-116

Koleini Mamaghani N, Shimomura Y, Iwanaga K, Katsuura T (2001) Changes in surface EMG and acoustic myogram parameters during static fatiguing contractions until exhaustion: Influence of elbow joint angles. J Physiol Anthrop Appl Human Sci 20 (2): 131140

Koleini Mamaghani N, Shimomura Y, Iwanaga K, Katsuura T (2000) Evaluation of muscle fatigue effected by elbow angle during sustained holding tasks. In Proc 5th Internat Cong Physiol Anthrop, Seoul, 253256

Lammert O, Jorgensen F, Einer-Jensen N (1976) Accelerometermyography (AMG), I: method for measuring mechanical vibrations from isometrically contracted muscles. In Komi PV ed. Biomechanics V-A, University Park Press, Baltimore, 152-164

Marchetti M, Salleo A, Figure F, Del Gaudio V (1974) Electromyographical and phonomyographical patterns in muscle atrophy in man. In Nelson RC, Morehouse CA eds. Biomechanics IV, Vol I, University Park Press, Baltimore, MD, 388-393

Matheson GO, Maffey-Ward L, Mooney M, Ladly K, Fung T, Zhang YT (1997) Vibromyography as a quantitative measure of muscle force production. Scand J Rehabil Med 29: 29-35

Maton B, Petitjean M, Cnockaert JC (1990) Phonomyogram and electromyogram relationships with isometric force reinvestigated in man. Eur J Appl Physiol 60: 194-201

Mealing D, Long G, McCarthy PW (1996) Vibromyographic recording from human muscles with known fiber composition differences. Br J Sports Med 30: $27-31$

Mealing D, McBride JW, Khan AZ (1990) Frequency domain analysis of muscle sound during fatigue of human quadriceps. In Proc IEEE/EMBS 12th Annu Internat Conf, 2215-2216

Mealing D, McCarthy PW (1991) Muscle sound frequency analysis from fast and slow twitch muscle. In Nagel JH, Smith WM eds. Proc IEEE-EMBS 13th Annu Internat Conf, New York, 948

Moritani T, Muro M, Nagata A (1986) Intramuscular and surface electromyogram changes during muscle fatigue. J Appl Physiol 60 (4): 1179-1185

Nagata S, Arsenault AB, Gagnon D, Smyth G, Mathieu PA (1990) EMG power spectrum as a measure of muscular fatigue at different levels of contraction. Med Biol Eng Comput 28: 374-378

Orizio C (1993) Muscle sound: Bases for the introduction of mechanomyographic signal in muscle studies. Crit Rev Biomed Eng 21 (3): 201-243

Orizio C, Esposito F, Veicsteinas A (1994) Effect of acclimatization to high altitude $(5,050 \mathrm{~m})$ on motor unit activation pattern and muscle performance. J Appl Physiol 77: 2840-2844

Orizio C, Liberati D, Locatelli C, De Grandis D, Veicsteinas A (1996) Surface mechanomyogram reflects muscle fibers twitches summation. J Biomech 29: 475-481

Orizio C, Perini R, Diemont B, Maranzana Figini M, Veicsteinas A (1990) Spectral analysis of muscular sound during isometric contraction of biceps brachii. J Appl Physiol 68 (2): 508-512

Orizio C, Perini R, Veicsteinas A (1989a) Changes of muscular sound during sustained isometric contraction up to exhaustion. J Appl Physiol 66 (4): 1593-1598

Orizio C, Perini R, Veicsteinas A (1989b) Muscular sound and force relationship during isometric contraction in man. Eur J Appl Physiol 58: 528-533

Oster G, Jaffe JS (1980) Low frequency sounds from sustained contraction of human skeletal muscle. Biophysical J 30: 119-128

Pan ZS, Zhang YT, Parker PA (1989) Motor unit power spectrum and firing rate. Med Biol Eng Comput 27: 1418

Petrofsky JS, Phillips CA (1980) The effect of elbow angle on the isometric strength and endurance of the flexors in men and women. J Human Ergol 9: 125-131

Rodriques AA, Agre JC, Franke TM, Swiggum ER, Curt JT (1996) Acoustic myography during fatigue in postpolio and control subjects. Muscle Nerve 19: 384-387

Rodriques AA, Agre JC, Knudtson ER, Franke TM, Ng AV (1993) Acoustic myography compared to electromyography during isometric fatigue and recovery. Muscle Nerve 16: 188-192

Sacco P, Mclntyre DB, Jones DA (1994) Effects of length and stimulation frequency of fatigue of the human tibialis anterior muscle. J Appl Physiol 77: 1148-1154

Simonson E, Weiser PC (1976) Psychological aspects and physiological correlates of work and fatigue. 1st ed. Vol 1, Illinois, Springfield

Shinohara M, Kouzaki M, Yoshihisa T, Fukunaga T (1998) Mechanomyogram from the different heads of the quadriceps muscle during incremental knee extension. Eur J Appl Physiol 78: 289-295

Stokes MJ, Cooper RG (1992) Muscle sounds during voluntary and stimulated contractions of the human adductor pollicis muscle. J Appl Physiol 72: 1908-1913 
Stokes MJ, Dalton PA (1991a) Acoustic myographic activity increases linearly up to maximal voluntary isometric force in the human quadriceps muscle. J Neuro Sci 101: 163-167

Stokes MJ, Dalton PA (1991b) Acoustic myography for investigating human skeletal muscle fatigue. J Appl Physiol 71: 1422-1426

Stokes MJ, Moffroid MS, Rush S, Haugh LD (1988) Comparison of acoustic and electrical signals from erectores spinae muscles. Muscle Nerve 2: 331-336

Vaz MA, Herzog W, Zhang YT, Leonard TR, Nguyen H (1996) Mechanism of electrically elicited muscle vibrations in the insitu cat soleus muscle. Muscle Nerve 19: $774-776$

Vaz MA, Herzog W, Zhang YT, Leonard TR, Nguyen H (1997) The effect of muscle length on electrically elicited muscle vibrations in the In-situ cat soleus muscle. J Electromyogr Kinesiol 7: 113-121

Wee AS, Ashley RA (1989) Vibrations and sounds produced during sustained voluntary muscle contraction. Electromyogr Clin Neurophysiol 29: 333337

Weir JP, Ayers KM, Lacefield JF, Walsh KL (2000) Mechanomyographic and electromyographic responses during fatigue in humans: influence of muscle length. Eur J Appl Physiol 81: 352-359

Weir JP, McDonough AL, Hill VJ (1996) The effects of joint angle on electromyographic indices of fatigue. Eur J Appl Physiol 73: 387-392
Yoshitake Y, Moritani T (1999) The muscle sound properties of different muscle fiber types during voluntary and electrically induced contractions. J Electromyogr Kinesiol 9: 209- 217

Zhang YT, Frank CB, Rangayyan RM, Bell GD (1992) A comparative study of simultaneous vibromyography and electromyography with active human quadriceps. IEEE Trans Biomed Eng 39 (10): 1045-1052

Zhang YT, Ladly KO, Rangayyan RM, Frank CB, Bell GD, Liu ZQ (1990) Muscle contraction interference in acceleration vibroarthrography. In Proc IEEE/EMBS 12th Annu Internat Conf, 2150-2151

Zwarts MJ, Keidel M (1991) Relationships between electrical and vibratory output of muscle during voluntary contraction and fatigue. Muscle Nerve 14: $756-761$

Zwarts MJ, Van Weerden TW, Haenen HTM (1987) Relationship between average muscle fiber conduction velocity and EMG power spectra during isometric contraction, recovery and applied ischemia. Eur J Appl Physiol 56: 212-216

Received: September 7, 2001

Accepted: October 16, 2001

Correspondence to: Nasser Koleini Mamaghani, Ergonomics Section, Department of Design and Architecture, Faculty of Engineering, Chiba University, 1-33 Yayoi-Cho, Inage-Ku, Chiba 263-8522, Japan e-mail: nasser@ergo1.ti.chiba-u.ac.jp 